\title{
Integration of mitigation and adaptation in urban climate change action plans in Europe: A systematic assessment
}

DOI:

10.1016/j.rser.2019.109623

\section{Document Version}

Accepted author manuscript

Link to publication record in Manchester Research Explorer

\section{Citation for published version (APA):}

Grafakos, S., Viero, G., Reckien, D., Trigg, K., Vigiue, V., Sudmant, A., Graves, C., Foley, A., Heidrich, O., Mirailles, J., Carter, J., Chang, L., Nador, C., Liseri, M., Chelleri, L., Orru, H., Orru, K., Aelenei, R., Bilska, A., ... Dawson, R. (2020). Integration of mitigation and adaptation in urban climate change action plans in Europe: A systematic assessment. Renewable and Sustainable Energy Reviews, 121, [109623]. https://doi.org/10.1016/j.rser.2019.109623

\section{Published in:}

Renewable and Sustainable Energy Reviews

\section{Citing this paper}

Please note that where the full-text provided on Manchester Research Explorer is the Author Accepted Manuscript or Proof version this may differ from the final Published version. If citing, it is advised that you check and use the publisher's definitive version.

\section{General rights}

Copyright and moral rights for the publications made accessible in the Research Explorer are retained by the authors and/or other copyright owners and it is a condition of accessing publications that users recognise and abide by the legal requirements associated with these rights.

\section{Takedown policy}

If you believe that this document breaches copyright please refer to the University of Manchester's Takedown Procedures [http://man.ac.uk/04Y6Bo] or contact uml.scholarlycommunications@manchester.ac.uk providing relevant details, so we can investigate your claim.

\section{OPEN ACCESS}




\section{Journal Pre-proof}

Integration of mitigation and adaptation in urban climate change action plans in Europe: A systematic assessment

S. Grafakos, G. Viero, D. Reckien, K. Trigg, V. Viguie, A. Sudmant, C. Graves, A. Foley, O. Heidrich, J.M. Mirailles, J. Carter, L.H. Chang, C. Nador, M. Liseri, L.

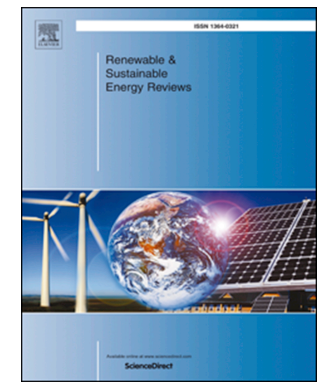
Chelleri, H. Orru, K. Orru, R. Aelenei, A. Bilska, B. Pfeiffer, Q. Lepetit, J.M. Church, M. Landauer, A. Gouldson, R. Dawson

PII: S1364-0321(19)30830-5

DOI: https://doi.org/10.1016/j.rser.2019.109623

Reference: RSER 109623

To appear in: Renewable and Sustainable Energy Reviews

Received Date: 10 February 2019

Revised Date: 7 November 2019

Accepted Date: 23 November 2019

Please cite this article as: Grafakos S, Viero G, Reckien D, Trigg K, Viguie V, Sudmant A, Graves C, Foley A, Heidrich O, Mirailles JM, Carter J, Chang LH, Nador C, Liseri M, Chelleri L, Orru H, Orru K, Aelenei R, Bilska A, Pfeiffer B, Lepetit Q, Church JM, Landauer M, Gouldson A, Dawson R, Integration of mitigation and adaptation in urban climate change action plans in Europe: A systematic assessment, Renewable and Sustainable Energy Reviews (2019), doi: https://doi.org/10.1016/j.rser.2019.109623.

This is a PDF file of an article that has undergone enhancements after acceptance, such as the addition of a cover page and metadata, and formatting for readability, but it is not yet the definitive version of record. This version will undergo additional copyediting, typesetting and review before it is published in its final form, but we are providing this version to give early visibility of the article. Please note that, during the production process, errors may be discovered which could affect the content, and all legal disclaimers that apply to the journal pertain.

(c) 2019 Published by Elsevier Ltd. 


\section{Integration of mitigation and adaptation in urban climate change action plans in Europe: A systematic assessment}

Author names and affiliations: Grafakos, S. ${ }^{1,2}$, Viero, G. ${ }^{3}$, Reckien, D. ${ }^{4}$, Trigg, K. ${ }^{1}$, Viguie, V. ${ }^{5}$, Sudmant, A. ${ }^{6}$, Graves, C. ${ }^{6}$, Foley, A. ${ }^{7}$, Heidrich, O. ${ }^{8}$, Mirailles, J.M. ${ }^{9}$, Carter, J. ${ }^{10}$, Chang, L.H. ${ }^{11}$, Nador, C. ${ }^{12}$, Liseri, M. ${ }^{1}$, Chelleri, L. ${ }^{13}$, Orru, H. ${ }^{14}$, Orru, K. ${ }^{15}$, Aelenei, R. ${ }^{16}$, Bilska, A. ${ }^{17}$, Pfeiffer, B. ${ }^{4}$, Lepetit, Q. ${ }^{4}$, Church, J.M. ${ }^{18}$, Landauer, M. ${ }^{19,20}$, Gouldson, A. ${ }^{6}$, Dawson, R. ${ }^{8}$

1 = Institute for Housing and Urban Development Studies, Burgemeester Oudlaan 50, 3062 PA, Rotterdam, The Netherlands

2= Global Green Growth Institute, 21-15 Jeongdong-gil, Jung-gu, 4518, Seoul, South Korea

3 = ECOR by Noble Environmental Technologies, Noorderpoort 30, 5916 PJ, Venlo, The Netherlands

4 = University of Twente, PO Box 217, 7500 AE Enschede, The Netherlands

5 = CIRED, Site du Jardin Tropical, 45bis, Av de la Belle Gabrielle, F-94736 Nogent-surMarne, France

$6=$ The University of Leeds, School of Earth and Environment, University of Leeds, Leeds, LS2 9JT, United Kingdom

7 = Queen's University Belfast, School of Mechanical \& Aerospace Engineering, Queen's University Belfast, Ashby Building, Stranmillis Road, Belfast BT9 5AH, United Kingdom 8 = Newcastle University, School of Engineering, Tyndall Centre for Climate Change, Newcastle upon Tyne NE1 7RU, United Kingdom

9 = Ramboll, Hannemanns Allé 53, DK-2300 Copenhagen S, Denmark

$10=$ University of Manchester, Oxford Road, Manchester, M139PL, United Kingdom

$11=$ Greenpeace, Chongqing South Road, 10045, Taipei City, Taiwan

$12=$ Independent researcher

13 = Universitat Internacional de Catalunya UIC, School of Architecture, Inmaculada 22, 08017, Barcelona, Spain

14 = Institute of Family Medicine and Public Health, University of Tartu, Ravila 19, 50411, Tartu, Estonia

$15=$ Institute of Social Sciences, University of Tartu, Lossi 36, 51003, Tartu, Estonia

$16=$ Independent researcher

17 = Poznan Municipal Town Planning Office, Dworcowa 16 b, 62-007 Biskupice, Poland (private address)

18 = Université de Reims Champagne-Ardenne, 57 rue Pierre Taittinger 51571 Reims Cedex, France

$19=$ University of Lapland, Arctic Centre, P.O. Box 122 (Pohjoisranta 4), 96101 Rovaniemi, Finland

20 = International Institute for Applied Systems Analysis (IIASA), Risk and Resilience Program, Schlossplatz 1, A-2361, Laxenburg, Austria

\footnotetext{
${ }^{1}$ corresponding author details, stelios.grafakos@gggi.org. Present address Global Green Growth Institute, 21-15 Jeongdong-gil, Jung-gu, 4518, Seoul, South Korea
} 
Abstract: Cities are major drivers of energy consumption and greenhouse gas emissions-the sources of anthropocentric climate change, whilst also concentrating people, buildings, and infrastructures and therefore potential risk and impacts of the latter. As a consequence, planning for climate change in urban areas does not only provide the opportunity but should necessitate considering interactions between mitigation and adaptation actions. However, existing research found that only a minority of urban areas consider both mitigation and adaptation in their climate action plans, i.e. 147 Climate Change Action Plans (CCAPs) were identified among a representative sample of 885 European cities. We investigate these 147 CCAPs to understand the degree of integration of adaptation and mitigation and draw implications for the maximization of synergies and co-benefits of such a combined approach. Using the developed scoring framework to evaluate the level of integration of CCAPs, the research finds that most of the plans reveal a 'moderate' level of integration. Moderate integration characterizes a plan that identifies sources of emissions and vulnerabilities to climate change, as well as some qualitative consideration of the synergies, but one that lacks a systematic consideration of potential integration opportunities. Furthermore, the analysis reveals that one of the main gaps of the evaluation and implementation of more integrated climate change actions in cities is the insufficient quantitative evaluation of the costs and funding schemes for adaptation and mitigation action implementation.

Keywords: urban; planning; European cities; interrelationships; synergies; co-benefits; scoring; evaluation

Word Count: 10,000 (maximum for a Review article)

List of abbreviations including units and nomenclature:

$\begin{array}{ll}\text { Ad/Mit } & \text { Adaptation/Mitigation } \\ \text { AMIA tool } & \text { Adaptation and Mitigation Interaction Assessment tool } \\ \text { CCAPs } & \text { Climate Change Action Plans } \\ \text { CCPC } & \text { Cities for Climate Protection Campaign } \\ \text { EC } & \text { European Commission } \\ \text { EU } & \text { European Union } \\ \text { GHGs } & \text { Greenhouse gases } \\ \text { ICLEI } & \text { Local Governments for Sustainability } \\ \text { UA } & \text { Urban Audit } \\ \text { UCCII } & \text { Urban Climate Change Integration Index } \\ \text { UK } & \text { United Kingdom }\end{array}$

\section{Introduction}

Preventing dangerous climate change will require immediate and effective action to mitigate greenhouse gas emissions [1]. Furthermore, ongoing and historical emissions and the long timescales over which these emissions affect the climate will require adaptation actions to manage the risks of committed climate change [2].

Globally, cities have emerged as leading climate change adaptation and mitigation actors, reflecting both a shift towards a more bottom-up approach to climate action (as seen in the Paris Agreement) and the unique capacities of urban policymakers to implement climate 
policies [3]. For example, in 2018, nearly 8,000 urban areas and other local and regional administrations from every continent (excluding Antarctica), representing almost $10 \%$ of the global population, had set greenhouse gas (GHG) emissions reduction targets for their local territories [4]. Likewise, global adaptation efforts are increasing, in particular in large and economically strong cities. Climate adaptation is defined as "the process of adjustment to actual or expected climate and its effects" while mitigation is defined as "a human intervention to reduce the sources or enhance the sinks of greenhouse gases (GHGs)" [1].

Integration of these two dimensions of climate policy may provide far-reaching benefits [5], especially in cities [1,6], with the potential of enhancing synergies and reducing conflicts. The latter can lead to more cost-efficient outcomes, and avoid maladaptation (the "problem of increasing risks from adaptation" [7, p211]) as well as malmitigation (i.e. increasing risks from mitigation)[8][]. Furthermore, sources of funding can be collated, knowledge can be consolidated, and more holistic, systems-based approaches can be implemented [9]. Realising these benefits requires a better understanding of the progress that urban areas may have made in integrating climate actions [10]. Previous research has shown that cities have started to take actions towards a more integrated approach in climate change planning $[11,12,13]$, although only a minority of cities' action plans considered both climate policies and even fewer implement integrated adaptation and mitigation plans [14].

To redress this knowledge gap, this study reviews and evaluates 147 CCAPs from a sample of 885 cities in Europe [7, 49]. The 885 cities are regionally representative according to population shares across European countries and covers both large and medium-sized cities. Of these 885 cities, 147 cities (17\%) have undertaken both adaptation and mitigation planning in an integrated manner. Of the other 738 cities, $62(7 \%)$ had separate adaptation and mitigation plans and $376(42 \%)$ had only a mitigation plan. Only 12 cities (1\%) had just an adaptation plan, whilst 288 (33\%) lacked any form of stand-alone local climate plan [7]. Reckien et al. [7] identify a number of factors that can influence the development and integration of local climate plans, which include national level policies (for both developing and integrating plans) and membership of international climate networks (for developing plans, however not necessarily a driver for integration). However, this work did not analyse the levels of integration between adaptation and mitigation, or the potential drivers, barriers, advantages and possible drawbacks of integrating mitigation and adaptation planning.

This study builds upon this research by 1) evaluating the level of integration of adaptation and mitigation in local Climate Change Action Plans (CCAPs) in Europe; 2) identifying the synergies and co-benefits of integration of adaptation and mitigation; and, 3) distilling best practices for other municipalities. Following this introduction, Section 2 explores the existing literature on the integration of mitigation and adaptation planning in the urban context. Section 3 describes the evaluation framework that has been developed. Section 4 presents the results and Section 5 evaluates and discusses them in the broader context of the literature before concluding in Section 6 .

\section{Literature review}

Integrated mitigation and adaptation planning shifted from national $[16,17,18]$ to local planning in the early 2000s [15] following evidence of significant synergies between different climate action approaches $[19,20,10]$. These studies established the scale and importance of synergies and possible conflicts and trade-offs between adaptation and mitigation 
measures. Furthermore, these studies suggested that urban policymakers can maximise positive synergies and minimize conflicts in climate action planning by involving the widest range of stakeholders in decision-making processes and by developing methodologies to enable the comprehensive inclusion of complementary strategies for climate change action. Local authorities are increasingly developing and adopting local climate plans (Reckien et al., 2014, 2018), often with the support of partnerships from different sectors and multiple governance levels [25, 26, 24]. Local authorities and cities are highly vulnerable to climate impacts, for example slow-onset events such as sea-level rise, and extreme events such as storm surges, flash floods, and heatwaves, which are in turn causing increased costs, health impacts and reduced well-being [21, 22, 23]. At the same time urban areas are sources of GHG emissions. Both aspects make cities play a central role in local climate adaptation and mitigation planning $[24,8]$. In comparison to rural areas, urban areas are often in greater need of adaptation actions due to the concentration of population and their greater reliance on urban infrastructure systems, which call for an improved understanding of the best adaptation measures in response to climate risks [19, 27].

There is a growing number of local climate and sustainability initiatives, for instance, the Local Governments for Sustainability (ICLEI) which represent more than $25 \%$ of global urban population [28] and the Cities for Climate Protection Campaign (CCPC), both act to reduce and offset GHG emissions through research and development of best practices, and sharing experiences between cities. The C40 Cities Climate Leadership Group [29] brings together more than 100 of the world's largest cities. Initiatives have also been taken at the European level with the European Union's (EU) Covenant of Mayors for Climate and Energy, which currently has over 7,700 signatories and cities that have submitted an action plan [30]. In January 2017, the Global Covenant of Mayors for Climate \& Energy formally brought together the EU Covenant of Mayors and the Compact of Mayors - the world's two largest initiatives of cities and local governments - to advance city-level transition to a low emission and climate-resilient economy, and to demonstrate the global impact of local action [30]. Although recently ended, the Rockefeller Foundation ran the Climate and Resilience Initiative and the 100 Resilient Cities Network in support of the most vulnerable communities via global-reaching funding schemes, capacity building and advanced resilience solutions between 2013-2019 [31]. As cities try to balance their efforts to develop both mitigation and adaptation actions and plans, guidance is required to move towards a more integrated approach.

Several studies have investigated the urban GHG emissions reduction potential (as mitigation) in different sectors [25, 32], and/or the potential to decrease the urban climate vulnerability and impacts for human and environmental systems (as adaptation) [2, 7]. A study on 885 European cities found that 147 cities (16.6\%), considered both adaptation and mitigation policy objectives in their CCAPs [7]. A similar study of 20 CCAPs from US municipalities found that mitigation discourses prevailed over adaptation strategies to tackle climate challenges [25]. However, this study did not consider the integration and interactions of adaptation and mitigation in cities' climate action planning.

There are an increasing number of studies focus on the review of CCAPs with a focus on different aspects of climate change planning in cities, such as on climate change actions in Europe [33, 8, 5, 7], adaptation strategies [34, 2], GHG emissions reduction strategies [32, $35]$, and ecosystem services [36, 37]. However, most studies continue to analyse mitigation 
and adaptation in isolation. Moreover, there is a lack of a comprehensive and systematic CCAPs analysis investigating the level of integration and interrelationships of adaptation and mitigation policy objectives and the extent to which this effects outcomes [19, 39, 40].

Grafakos et al. [41] developed an evaluation framework of variables and a scoring system for the three phases of mitigation-adaptation planning which) identifying and understanding phase, ii) envisioning and planning phase, and iii) the implementation and monitoring phase. The framework was tested in a small number of global cities (9) emphasizing the need for broader application of the evaluation framework in order to assess and compare the level of integration of adaptation and mitigation in different cities' CCAPs.

The analysis of interrelationships within literature on European integrated CCAPs defines interrelationships indistinctively [14], the current study distinguishes instead between positive (co-benefits and synergies) and negative (conflicts and trade-offs) interrelationships. A cobenefit occurs when an adaptation (or mitigation) action leads to positive mitigation (or adaptation) effects, or vice versa. For instance, effective building envelopes that aim to reduce energy use and GHGs (mitigation) may lead to better insulation and improved indoor temperature comfort during warmer temperatures (adaptation co-benefit). In the context of this study, synergy occurs when an urban action that is not primarily aimed at either adaptation or mitigation (it could be aimed at both, or neither) leads to the simultaneous achievement of both mitigation and adaptation. An example of synergy relates to planting trees in urban areas, which can act as a carbon sink (mitigation benefit) and an urban cooling during hot weather (adaptation benefit). A conflict or a trade-off is reported when an adaptation (or mitigation) action leads to negative mitigation (or adaptation) effects. One example of a conflict is given by Tol [42], mentioning that conventional air conditioning aims to reduce the summer heat impact in indoor environments, while it simultaneously increases carbon emissions due to high energy demand.

Against this background, the aim of this paper is to identify interrelationships between adaptation and mitigation (i.e. co-benefits, synergies, trade-offs and conflicts) and evaluate the level of integration of these two typeset al [41]. Out of the overall 885 European CCAPs that were analyzed by Reckien and colleagues [7], the 147 CCAPs that currently combine adaptation and mitigation policies were evaluated. The analysis sheds light on how combined CCAPs in Europe identify and address adaptation-mitigation (Ad/Mit) interrelationships with the potential to significantly contribute to a better understanding of these interrelationships by sectors and by types of measures, with benefits for future integrated climate action policy-making in cities. Integrating both adaptation and mitigation into local climate action plans is of critical importance. To our knowledge, this is the first comprehensive study of this kind.

\section{Methodology}

\subsection{The sample: Climate Change Action Plans}

The selection of the sample is based on a detailed screening process of 885 CCAPs of Urban Audit (UA) database, now called "Statistics on European cities" in the EU-28, as was undertaken by Reckien and others [7]. This study identified that 147 CCAPs from 9 countries combine adaptation and mitigation policy objectives in the same plan. These 147 CCAPs 
(see Table 1) were reviewed and evaluated. According to the aforementioned study [7], the UA defines a city as a local administration unit where the majority of the world population lives: an urban centre of approximately 50,000 inhabitants. However, to ensure representativeness within countries and across the EU-28, the UA also includes some smaller urban areas with less than 50,000 inhabitants. In order to ensure a balanced and regionally representative sample, the UA adopted the following criteria: i) cities in each country should represent about $20 \%$ of the population in the country, ii) have a good geographical distribution (at least one city from each Nomenclature of Territorial Units-3 Region), and iii) vary in size to include large and small cities (including some urban centres with less than 50,000 inhabitants).

Reckien et al. [7] developed a typology and framework for analysis that classifies 885 CCAPs in the EU-28 based on two dimensions: the alignment with spatial (local, national and international) policies and other climate-related policy documents (see [7] for the detailed classification). In this study, the research sample of 147 CCAPs is classified as being 'comprehensive and stand-alone', as they were developed with a clear focus on climate change for an entire urban area as stand-alone climate policy documents.

The sample can be further classified as either Autonomous Plans (i.e. those prepared voluntarily by local government) or Regulatory Plans (i.e. those required by national regulation). Autonomous Plans analysed in this study are from Belgium (1), Germany (4), Finland (4), Ireland (1), Poland (1), Romania (1), and Spain (5). Regulatory Plans analysed in this study are from France (49) and United Kingdom (81). It should be noted that, while national governments provide policy guidance on the development and design of CCAPs, their contents and legal status is usually left to the discretion of local authorities [7]. The imbalanced composition of the sample with a large number of French and UK integrated CCAPs limits the comparability of the results at the national level.

Table 1. List of analyzed city CCAPs per country (in alphabetical order)

\begin{tabular}{|c|c|}
\hline Country & Number of CCAPs \\
\hline Belgium & 1 \\
\hline Finland & 4 \\
\hline France & 49 \\
\hline Germany & 4 \\
\hline Ireland & 1 \\
\hline Poland & 1 \\
\hline Romania & 1 \\
\hline Spain & 5 \\
\hline UK & 81 \\
\hline Total & $\mathbf{1 4 7}$ \\
\hline
\end{tabular}




\subsection{Methods and data}

All 147 country policy documents included in the analysis were reviewed by researchers who are native speakers. Data from the CCAPs was extracted using Content Analysis, an established practice in climate change planning research [5, 7, 34, 37, 2] to assure the impartiality of data analysis as the document analysts are external to city governments.

The Urban Climate Change Integration Index (UCCII) uses variables from this analysis to provide a comparative, comprehensive and standardized evaluation of the integration of $\mathrm{Ad} / \mathrm{Mit}$ actions. Indicators have been developed for each of the three planning stages, "Identifying and Understanding", "Envisioning and Planning" and "Implementation and Monitoring" [41], as shown in Table 2. Below, the colour coding shows the relation of each variable to mitigation (blue), adaptation (orange), integrated (dark green) and mitigation (grey).

Table 2: List of variables in the Urban Climate Change Integration Index (UCCII) uses and their associated scoring scales

\begin{tabular}{|c|c|c|c|}
\hline $\begin{array}{l}\text { Stage of } \\
\text { planning }\end{array}$ & Sub-stage & Variables & $\begin{array}{l}\text { Scoring } \\
\text { scale }\end{array}$ \\
\hline \multirow{9}{*}{$\begin{array}{l}\text { Identifying and } \\
\text { Understanding }\end{array}$} & \multirow{9}{*}{$\begin{array}{c}\text { Scientific } \\
\text { knowledge and } \\
\text { information }\end{array}$} & GHG emissions Profile & $0-1$ \\
\hline & & GHG Emissions Forecast & $0-2$ \\
\hline & & Vulnerability Profile & $0-2$ \\
\hline & & Future Climate Projections & $0-2$ \\
\hline & & $\begin{array}{l}\text { Both GHG Emissions and Vulnerability Profile } \\
\text { (constructed variable) })^{*}\end{array}$ & $0-1$ \\
\hline & & $\begin{array}{l}\text { Both Emissions Forecast and Climate Projections } \\
\text { (constructed variable) }^{*}\end{array}$ & $0-1$ \\
\hline & & Uncertainty of Climate Impacts & $0-1$ \\
\hline & & Cost Estimates of Damages of Climate Impacts & $0-1$ \\
\hline & & Climate Hazards detailed & $0-1$ \\
\hline \multirow{5}{*}{$\begin{array}{l}\text { Envisioning } \\
\text { and Planning }\end{array}$} & \multirow[t]{4}{*}{ Targets setting } & GHG emissions reductions targets & $0-2$ \\
\hline & & GHG emissions reduction sectoral targets & $0-1$ \\
\hline & & Adaptation Objectives & $0-2$ \\
\hline & & $\begin{array}{l}\text { Consideration of both } \mathrm{GHG} \text { reduction targets and } \\
\text { adaptation objectives (constructed variable) }{ }^{*}\end{array}$ & $0-1$ \\
\hline & Prioritization & Cost estimates of actions & $0-2$ \\
\hline
\end{tabular}




\begin{tabular}{|c|c|c|c|}
\hline & & Benefit estimates of actions & $0-2$ \\
\hline & & $\begin{array}{l}\text { Consideration of } \mathrm{Ad} / \text { Mit interrelationships (co- } \\
\text { benefits/synergies or trade-offs/conflicts) }\end{array}$ & $0-2$ \\
\hline & & Sustainability benefits & $0-1$ \\
\hline & Communication & Common (Ad/Mit) public education and outreach & $0-1$ \\
\hline Implementation & Financing & Common funding body or budget (public) & $0-1$ \\
\hline & & Financing commitment (public) & $0-1$ \\
\hline & Implementation & Mainstreaming potential of Climate Actions & $0-2$ \\
\hline & & Common policy or regulatory framework & $0-2$ \\
\hline & & Common coordination/implementation body & $0-1$ \\
\hline & & Partnerships & $0-2$ \\
\hline & Monitoring & Common Monitoring procedure/ framework & $0-2$ \\
\hline
\end{tabular}

Highest possible total score ${ }^{\star}$ These are additional composite variables constructed by combining two variables. These constructed variables are used in the subsequent analysis but the CCAPs score. For instance, the constructed variable "Both GHG Emissions and Vulnerability Profile" combines both "GHG Emissions Profile' and 'Vulnerability Profile' variables.

The majority of indicator responses were coded in binary form - if an indicator was fulfilled the CCAP was given a score of ' 1 ', if not it received a score of ' 0 '. Other variables were based on a scoring scale of ' $0-2$ ' as these indicators did not simply return a yes or no response. Of these variables, two were related to adaptation ("Vulnerability profile" and "Future climate projections"), two were related to mitigation ("GHG emissions forecast" and "GHG emissions reduction targets") and three were related to integration of the two policies ("Consideration of Ad/Mit interrelationships", "Mainstreaming of both Ad/Mit actions" and "Common Monitoring procedure/framework"). Appendix 1 illustrates the scoring mechanism behind these variables.

For the variable "Consideration of Ad/Mit interrelationships", we investigated whether the CCAPs have explicitly stated co-benefits, synergies, trade-offs or conflicts between mitigation and adaptation within the plans and identified the sectors that the interrelationships occurred.

Because only 9 of the above variables address integration a higher score from analysis of all variables does not necessarily indicate better integrated policies. Therefore, two types of analysis were conducted: i) including all the variables of the evaluation framework and ii) including only the 9 integrated variables. Spearman's rank correlation coefficient has been 
used to explore the level of convergence/ divergence between the score rankings of the two analyses.

To ensure that the CCAPs were reviewed in the same manner, minimising the subjectivity of scoring, detailed guidelines were developed on how to review and evaluate the CCAPs (Appendix 2). The guidelines also include indicator descriptions, score explanations, related keywords and scoring examples.

The results are clustered according to their scores (Section 4.2). In the analysis of all variables of the evaluation framework a score of ' $0-10$ ' is considered an 'early- stage' integrator; a score of '11-20' a 'moderate' integrator; whilst an 'advanced' integrator has a score of '20 or more'. In the analysis of the 9 integrated variables a score of $<4$ is an 'early' integrator; a score of 5-8 a 'moderate' integrator; whilst an 'advanced' integrator has a score 9-12'. "Early-stage integrators" incorporate a few integration elements in their CCAPs aiming to address primarily either mitigation or adaptation. "Moderate integrators" incorporate more integration elements in their CCAPs than the "early-stage integrators", while they are adopting a more balanced approach on addressing mitigation and adaptation which is observed in at least two planning stages. "Advanced integrators" incorporate integration elements in all stages of planning in their CCAPs while they are adopting a well-balanced approach on addressing mitigation and adaptation.

\section{Results}

\subsection{Evaluation of the level of adaptation and mitigation across different planning stages}

Based on the comprehensive review of cities' CCAPs, the sum of the frequencies of each of the variables that characterize the level of integration of adaptation and mitigation in the first planning phase "(Identifying and Understanding") is shown in Figure 1. It shows that 106 CCAPs (or $72.1 \%$ ) identify both the specific climate hazards to which those cities should adapt, and also have GHG emissions profiles that set out mitigation objectives (the highest frequency). Only 17 (or 11.5\%) plans include economic cost estimates of losses and damages caused by climate impacts (the lowest frequency). Looking specifically into the two green bars of the graph, which refer to the integration of adaptation and mitigation, 74 $(50.3 \%)$ CCAPs include both GHG emissions and vulnerability profiles. Finally, only 35 CCAPs, or $23.8 \%$, undertook emissions forecast and climate projections, which may suggest a limited technical capacity of many to undertake this. 


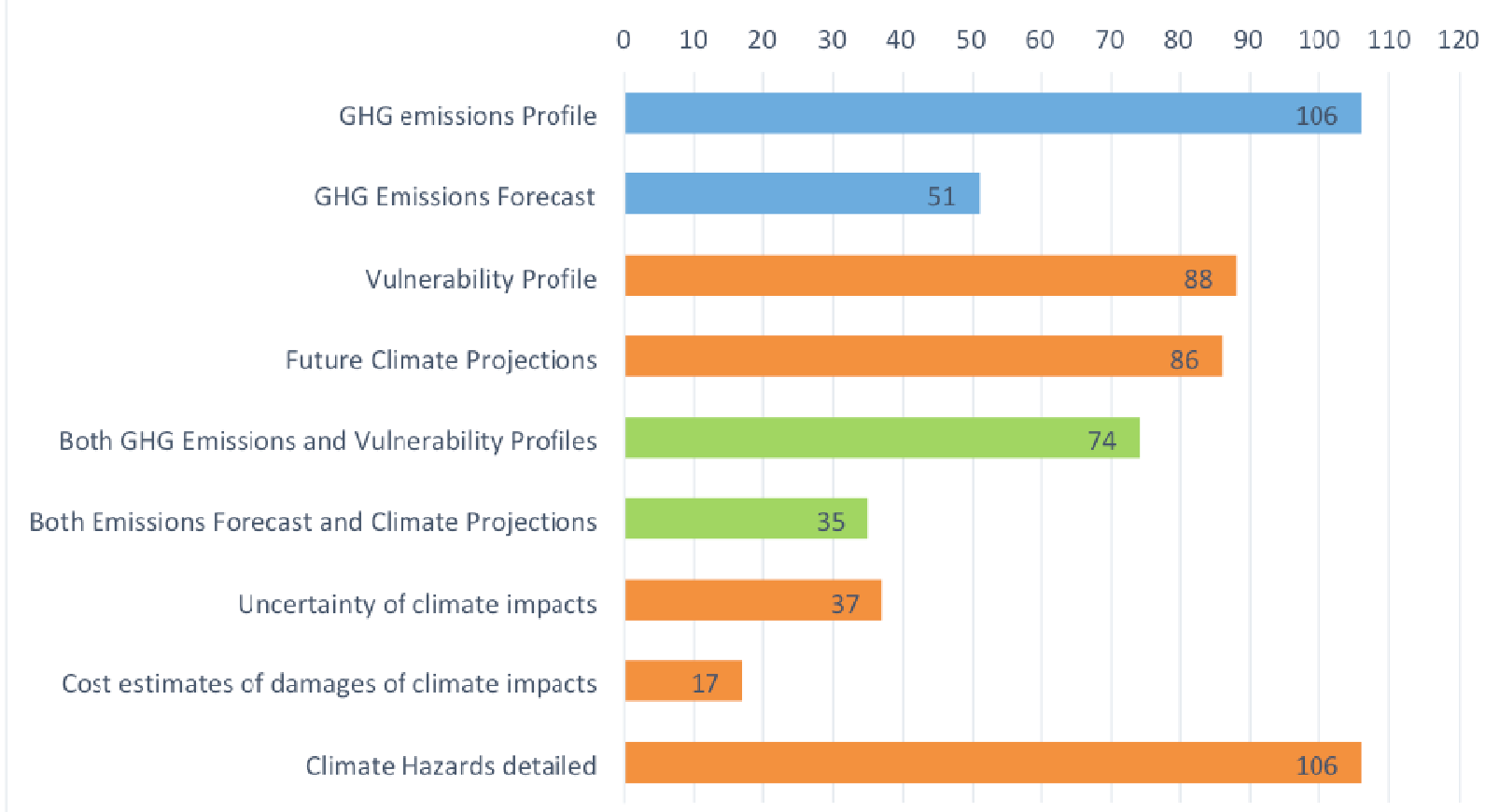

Figure 1. Identification of the level of adaptation and mitigation integration in the 'Identifying and Understanding stage' (Colours correspond to Table 2).

Figure 2 summarises the score components for the "Envisioning and Planning Stage" and shows that $111(75.5 \%)$ CCAPs have set city-level GHG emission reductions targets (the highest frequency). Figure 2 also shows that only 38 plans, or $25.8 \%$, of all CCAPs, have suggested Ad/Mit interrelationships during the prioritization process (lowest frequency) - and relates to one of the integrated variables of adaptation and mitigation. This will be considered further in Section 4.4.

However, also with regard to integration, notably, more than half, 84 (57.1\%) CCAPs consider both GHG reduction targets and adaptation objectives in their envisioning and planning stage, and 109 (74.2\%) CCAPs incorporate both concepts in common public education and outreach. 


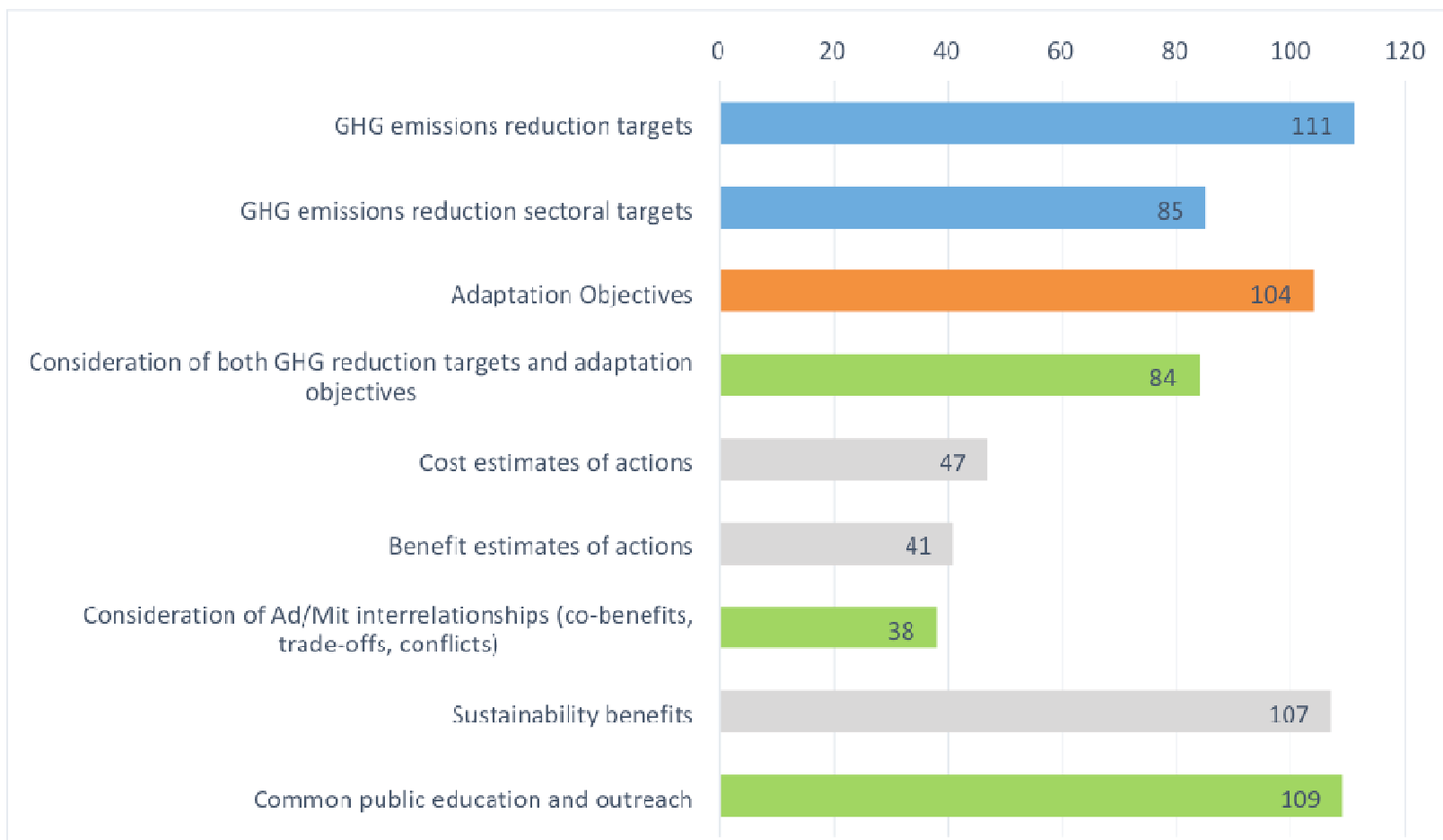

Figure 2. Identification of the level of adaptation and mitigation in the "Envisioning and Planning stage".

Finally, Figure 3 illustrates the UCCII components of the "Implementation and Monitoring planning stage". It shows that 108 plans, or $73.5 \%$, use partnerships (public-private, local other government, local government - civil society, etc.) to support the implementation of actions. In contrast, only 17 CCAPs $(11.6 \%)$ present a common source of funding body or budget at national or city level to finance a combined approach. The latter also captures the combination of adaptation and mitigation, which reveal a limitation of cities in implementing joint (public) funding bodies or taking budgetary decisions in relation to Ad/Mit. Regarding integration, Figure 3 also indicates that 97 city plans, or $66 \%$, have implemented common policy and/or regulatory frameworks, 69 CCAPs have common coordination/implementation bodies (46.9\%), and 85 have a common monitoring procedure/ framework (57.8\%). 


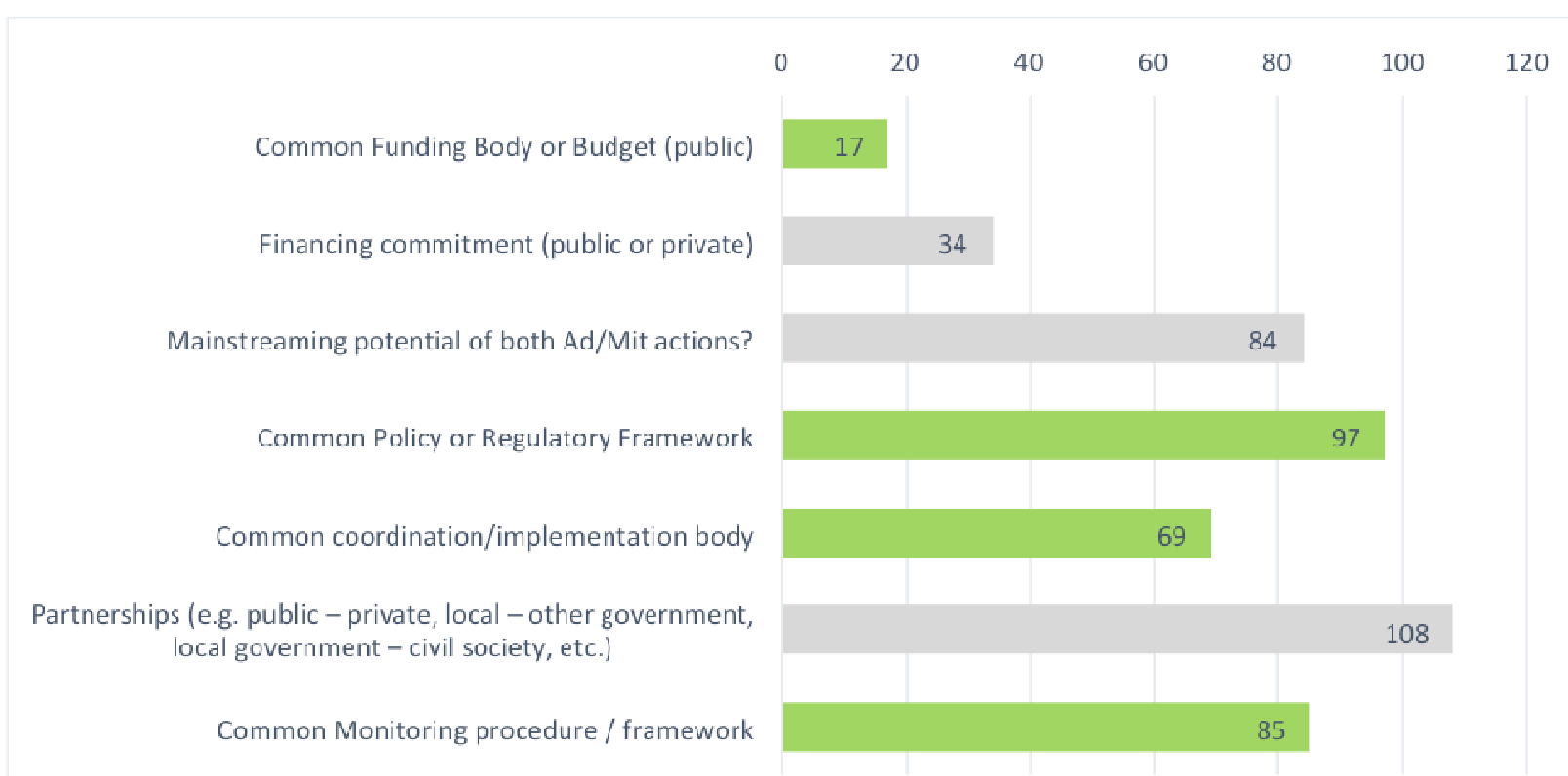

Figure 3. Identification of the level of adaptation and mitigation in the Implementation and Monitoring stage.

\subsection{Grouping integrators into clusters}

In Figures $4 \mathrm{a}$ and $4 \mathrm{~b}$, cities are grouped into 'early stage', 'moderate' and 'advanced' integrators as described in the methodology section. The Lorenz curve in Figure $4 \mathrm{a}$ is based on an analysis that combines both integrated and non-integrated variables, whereas Figure $4 \mathrm{~b}$ illustrates the scores based on the 9 integrated variables. Figure $4 \mathrm{a}$ shows 32 'early-' integrators (left-side of the vertical black line), 50 'moderate' level integrators (between the vertical black and orange lines) and 18 'advanced' integrators (right-side of the orange line).

The five highest integrators of all 147 cities (shown as orange dots) are Annemasse Agglomération (25) and Fréjus (25) in France, Coventry (26), Dundee City (29) and Southampton (30) in the UK. The complete list from the comprehensive review of all cities' CCAPs scores is shown in Appendix 3.

Figure $4 \mathrm{~b}$ shows the results for just the 9 integrated variables (highlighted in green in Table 2 ), the highest scoring cities resulted as follows: Cheshire West and Chester (11) in the UK, Annemasse Agglomeration (10) in France, Dundee City (10) as well as Southampton (10) in the UK. 


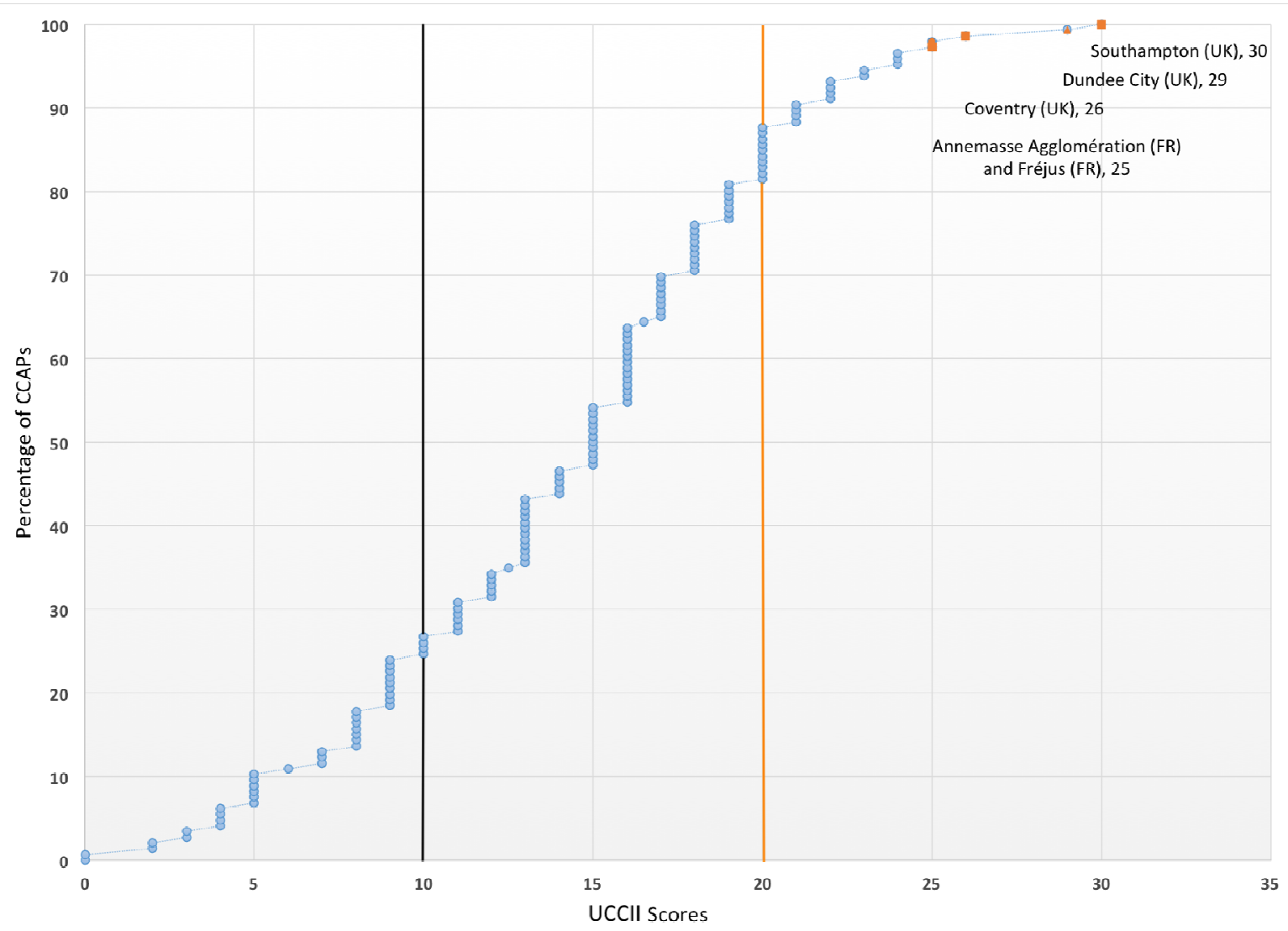

Figure 4a. Percentages of cities' UCCII scores with threshold of the three integrators clusters (based on the comprehensive assessment). 


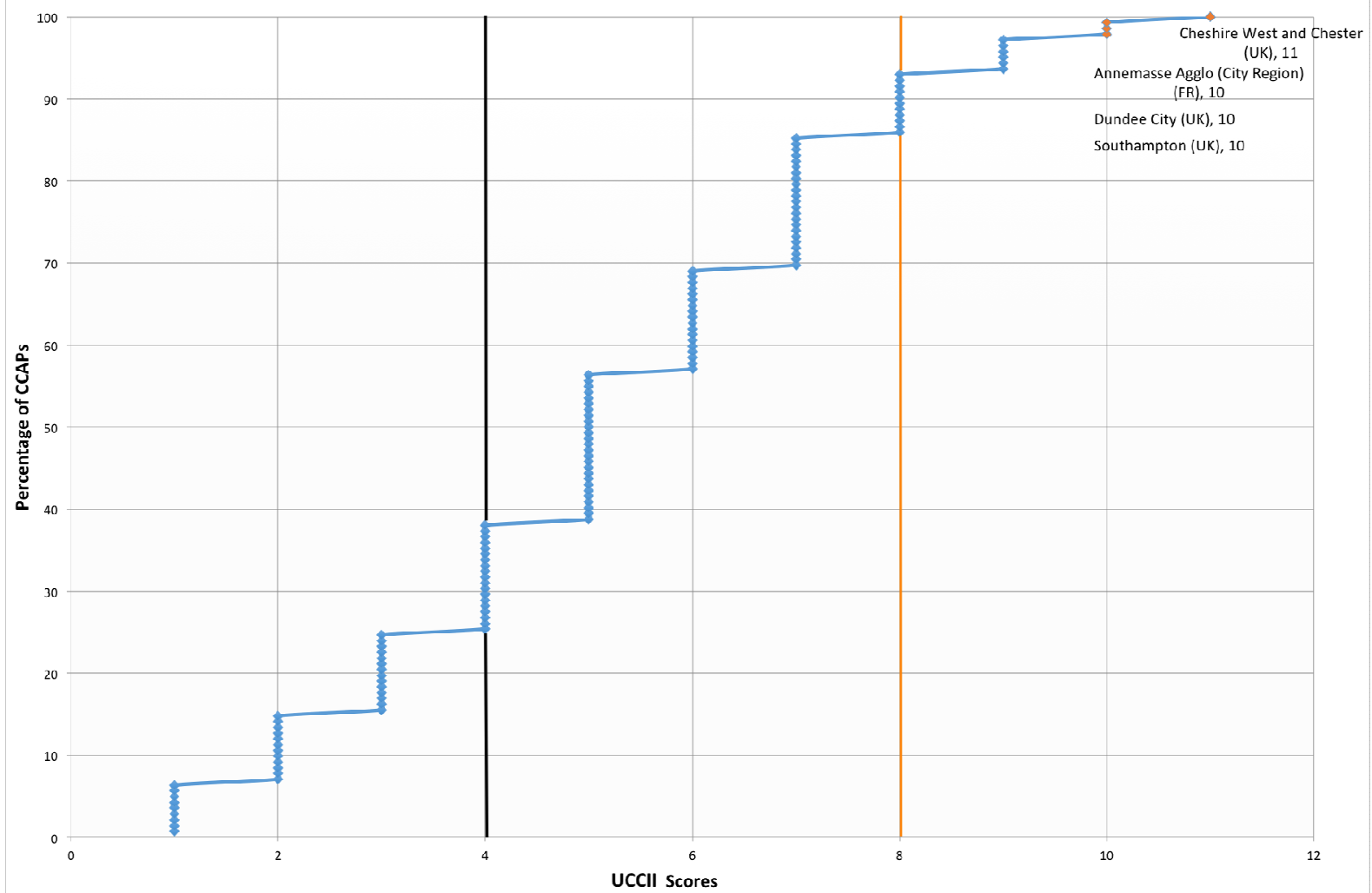

Figure 4b. Percentages of cities' UCCII scores with threshold of the three integrators clusters (based on the assessment with the 9 integrated variables).

The outcome of the Spearman's correlation coefficient analysis showed the variables were monotonically related, i.e. a high Spearman's correlation coefficient (0.9), suggests that the ranking of CCAPs based on their integrated scores is very similar to the ranking of CCAPs based on the analysis including all variables.

Overall, the analysis based on the 9 integration variables does not provide major changes in the UCCII ranking, even among the top cities. Notably, some differences exist, e.g. Coventry and Frejùs ranked 3rd and 4th, respectively, and they now both rank 5th. More importantly, Glasgow ranked 18th and now climbs to the 5th position. 


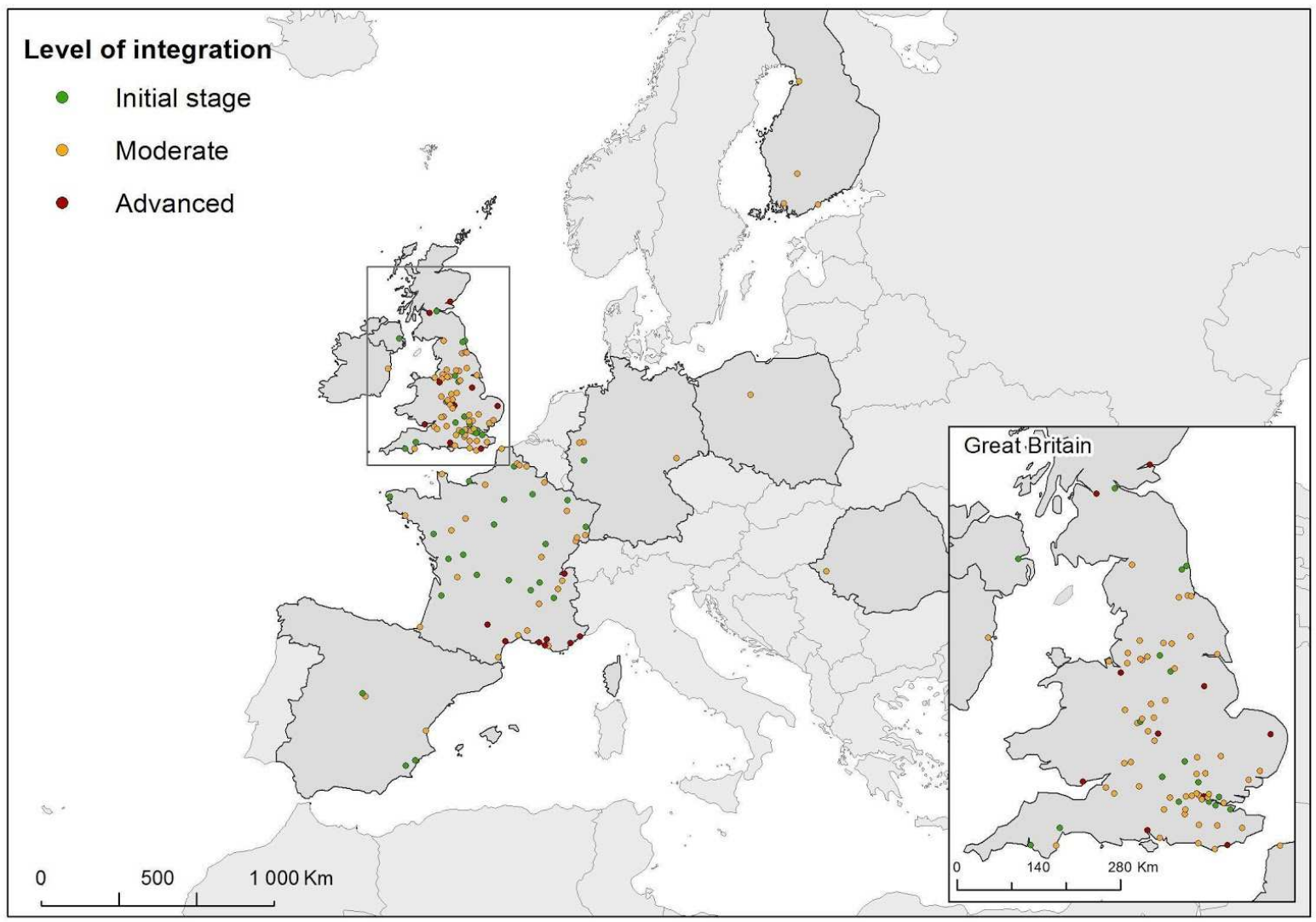

Figure 5. Map of the 147 cities grouped according to their UCClI score (based on the comprehensive assessment with all variables)

Figures 6 and 7 shows the average UCCII score per country. In order to reflect the imbalance between sample sizes in the UK and France, and the other countries, the plots are separated.

Belgium, Ireland, Romania and Poland are not included in Figure 6 as they have one reviewed CCAP each, and according to the evaluation, they all show a 'moderate' level of integration, except for Timisoara's CCAP (Romania) resulting in an early stage integrator.

In most countries, the majority of cities have low level of integration ('early-stage' integrators), except in Spain, where 3 out of 5 cities are 'moderate' integrators. On the contrary, 1 CCAP for Finland and Germany respectively accounts as 'moderate' integrator, and none of these countries features 'advanced' integrators.

In Figure 6b, France and the UK are compared given their high number of CCAPs that combine adaptation and mitigation. In the case of France, 51\% of its CCAPs are classified as 'early-stage' integrators, $47 \%$ as 'moderate' integrators and $2 \%$ as 'advanced' integrators. Furthermore, the analysis shows that $19 \%$ of UK cities' CCAPs are 'early-stage' integrators, $78 \%$ are 'moderate' and $3 \%$ are 'advanced' integrators. 


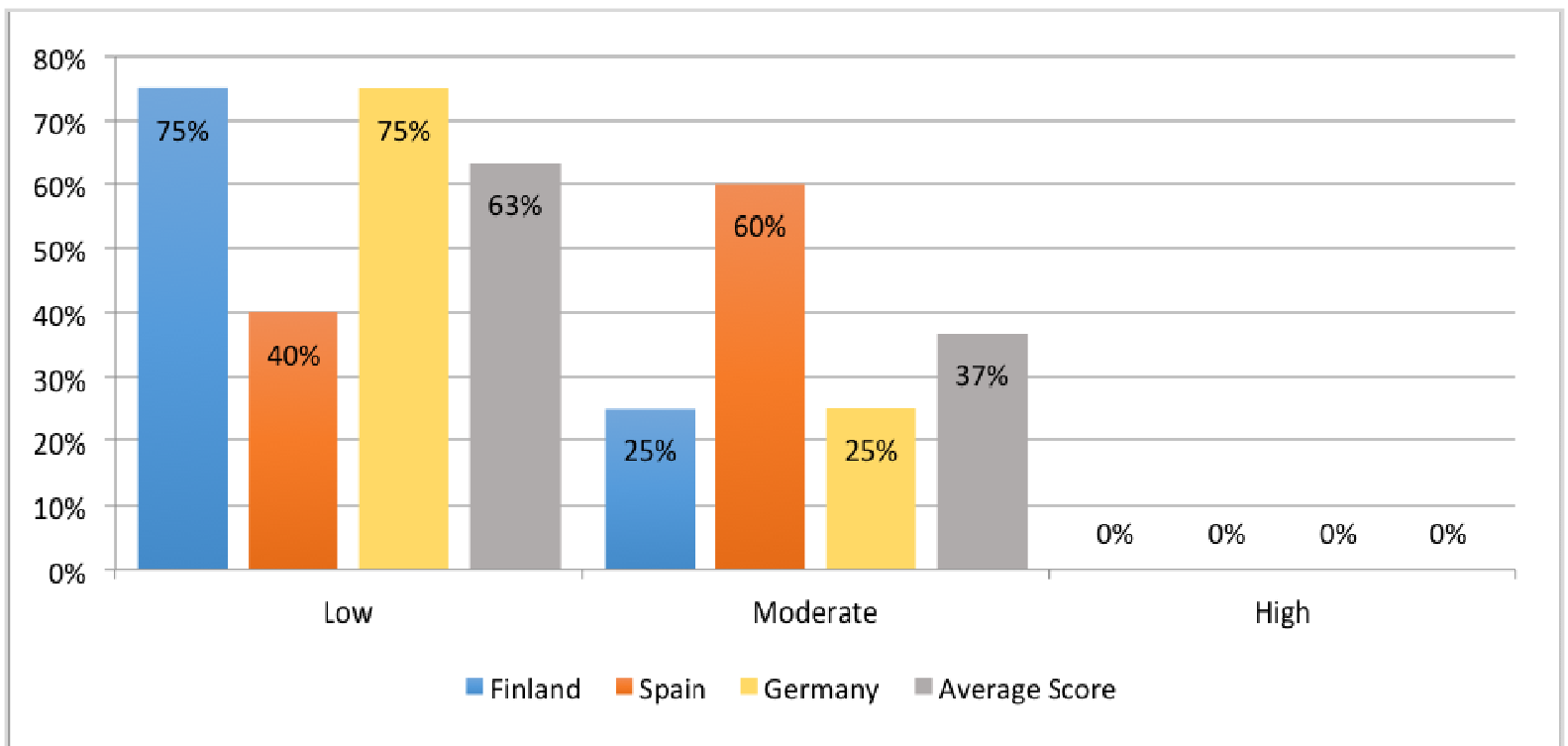

Figure 6a. Percentage of the 3 groups of integrators per country (for countries with 4-5 CCAPs).

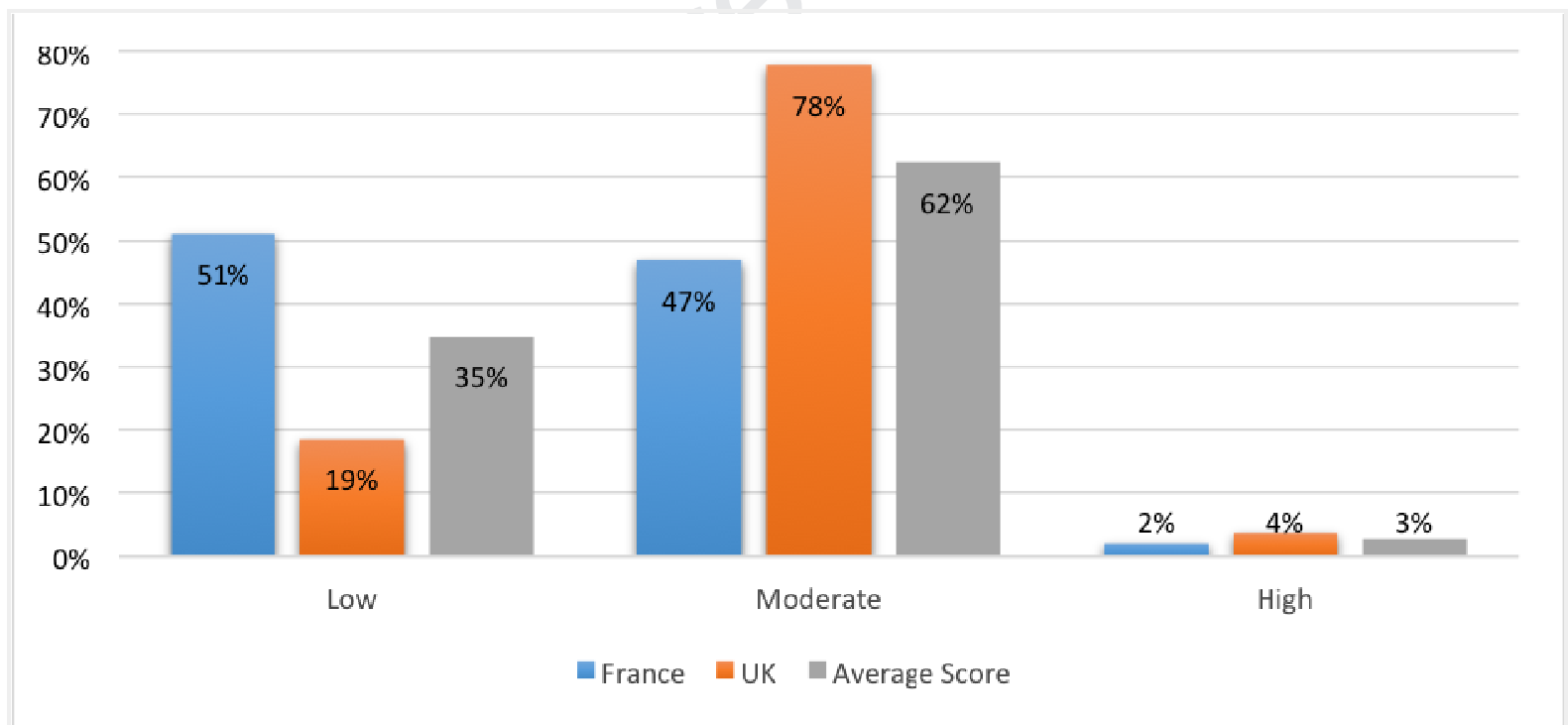

Figure $6 \mathrm{~b}$. Percentage of the 3 groups of integrators per country (for countries with large number of CCAPs - 49 and above).

\subsection{Country results and comparisons}

This section presents average UCCII score per country. Each score was obtained by aggregating the average score of each of the three stages of climate change action planning. Similar to 4.2, Belgium, Ireland, Romania and Poland are not included in the graph as they have only one reviewed CCAP which is an insufficient sample to assess the overall country performance in integrating adaptation and mitigation policy objectives at the local level. However, those individual cities could be considered climate frontrunners in their respective nations. 
Figure 7 (following the rationale of Figure 6 above) is split in two stacked bar charts, comparing average UCCII scores of a) countries with 4 to 5 CCAPs (i.e. Finland, Germany, Spain), and b) countries with a large number of CCAPs (i.e. France and UK), based on the assessment, including only the integrated variables. Figure 7a shows that Spain compared to the other countries with 4 and 5 CCAPs, has the highest average UCCII score (5.2)while Finland the lowest (4.25). Figure $7 \mathrm{~b}$ shows that the UK has the highest average UCCII score even if the country has the highest number of CCAPs.

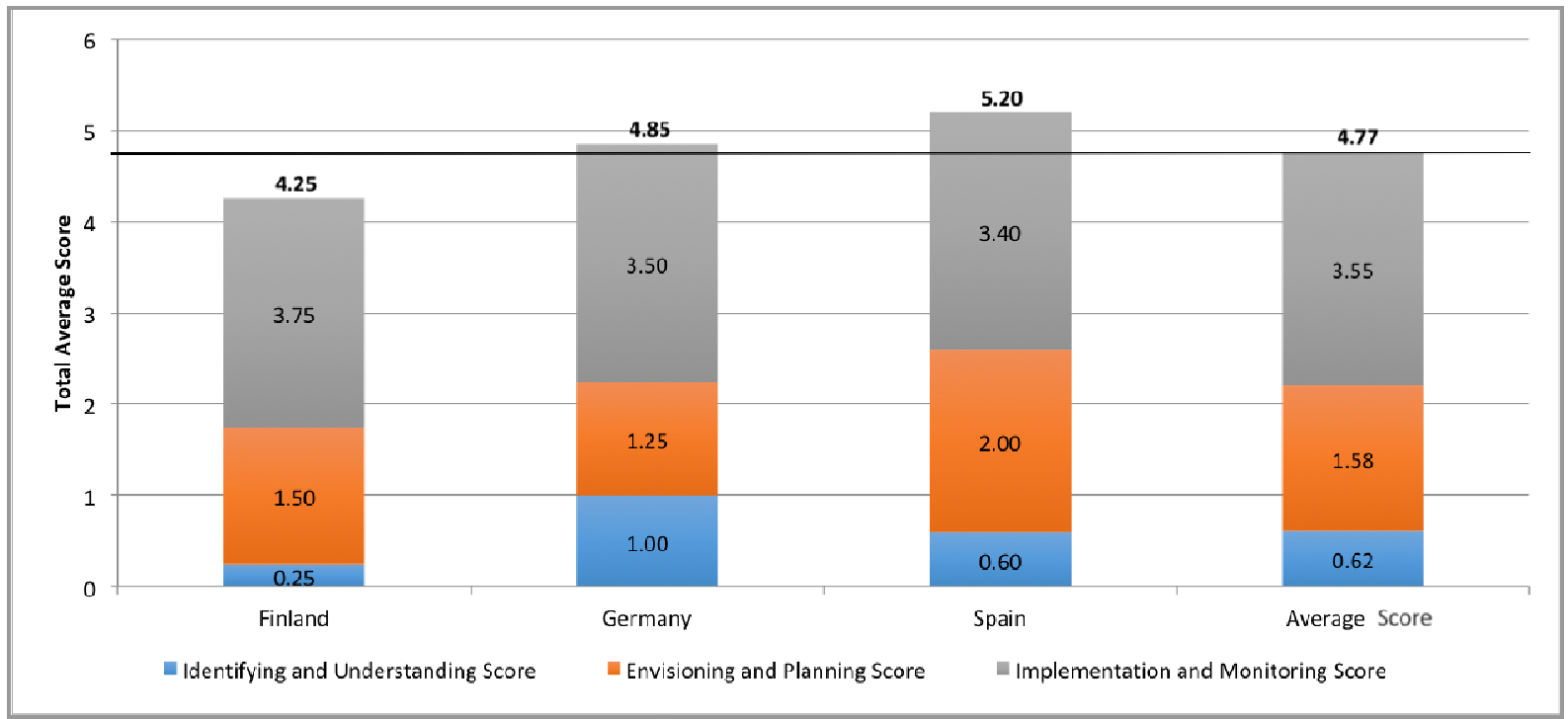

Figure 7a. Average of UCCII score per country (countries with only 4-5 CCAPs) based on assessment including only integrated variables.

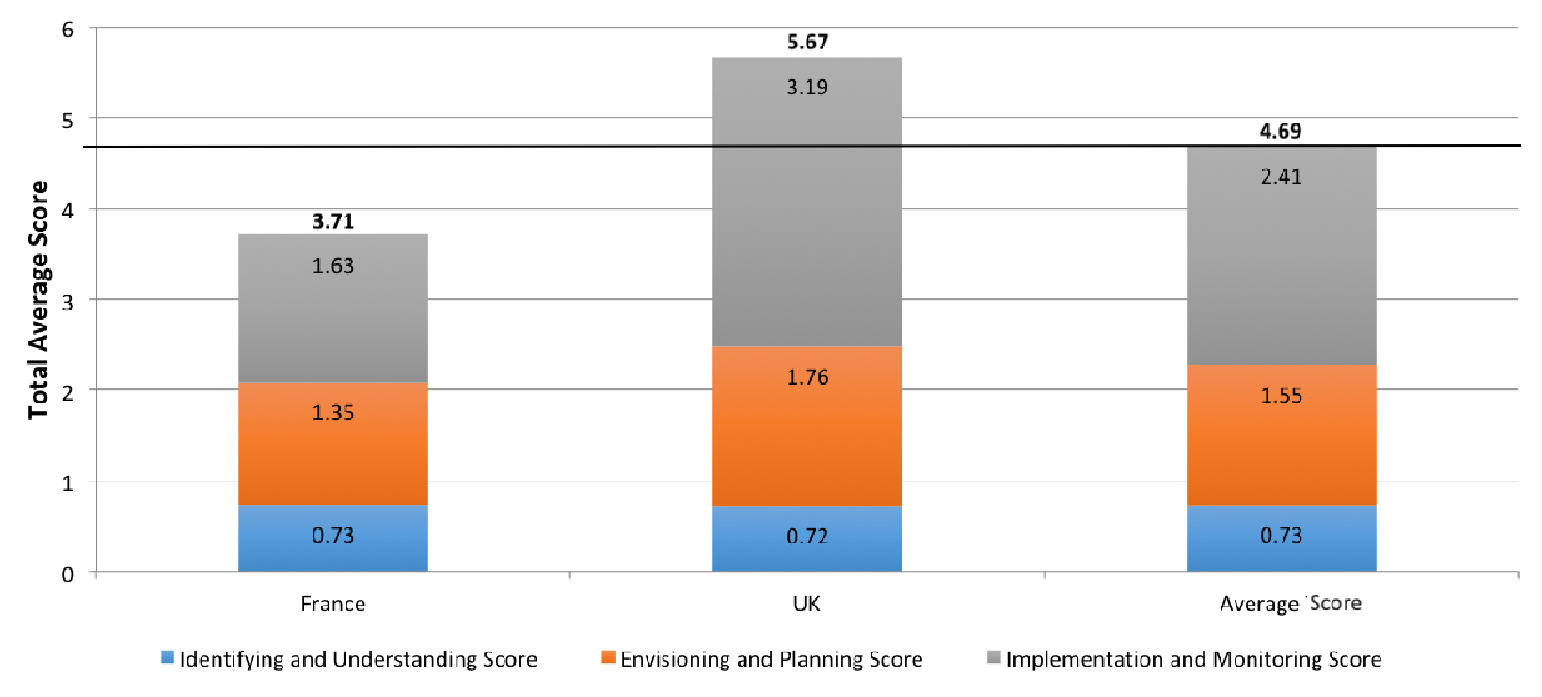

Figure 7b. Average UCCII score per country (countries with large number of CCAPs 49 and above) based on assessment including only integrated variables. 


\subsection{Ad/Mit Interrelationships across sectors and policy objectives}

This section focuses on just the indicator "Consideration of Ad/Mit interrelationships". The proportion of $\mathrm{Ad} / \mathrm{Mit}$ interrelationships identified in one or multiple different sectors is shown in Figure 8a. From the seven sectors considered within the Ad/Mit interrelationships analysis and 52 comprehensive interrelationships, nearly $32 \%$ of interrelationships were found in "Green infrastructure". Other interrelationships were identified in "Construction, energy efficiency and building" (23\%) and in "Education and communication" (15\%), whilst approximately $10 \%$ in "Planning". The rest of interrelationships are "Flood/water management" (approximately 8\%), "Transport" (approximately 8\%) and "Consumption" (approximately 4\%).

\section{A. Total Ad/Mit interrelationships}
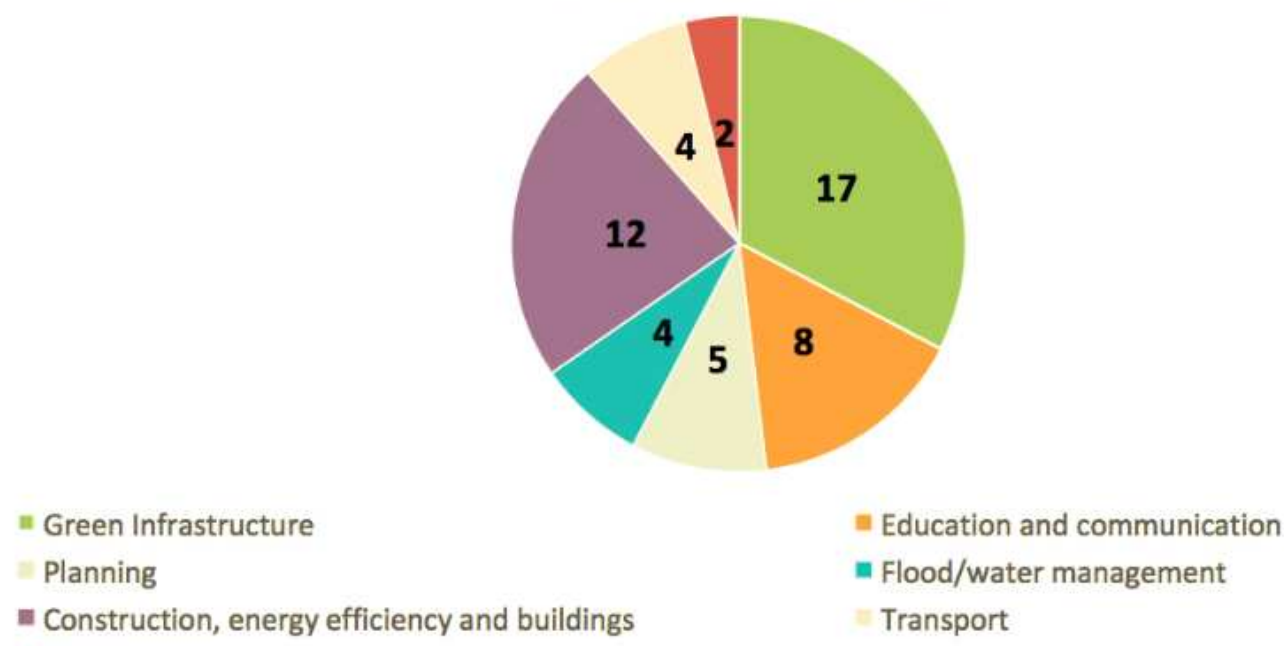

- Consumption

B. Type of interrelationship

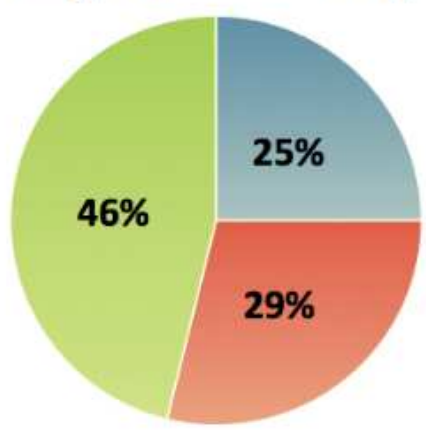

= Adaptation actions with mitigation co-benefits = Mitigation actions with adaptation co-benefits $=$ Ad/Mit synergies

Figure 8a: Overall Ad/Mit Interrelationships in different sectors and figure 8b: Overall number of interrelationships based on primary policy objectives (b).

Figure $8 \mathrm{~b}$ shows the percentage of interrelationships that have either adaptation actions with mitigation co-benefits (25\%), mitigation actions with adaptation co-benefits (29\%) or Ad/Mit 
synergies (46\%). Notably, none of the reviewed CCAPs identified any trade-offs or conflicts of adaptation and mitigation actions.

\section{Discussion}

\subsection{Integration of mitigation and adaptation}

About two thirds (71\%) of CCAPs include a GHG emissions profile, whereas $60 \%$ of them include a vulnerability profile, suggesting that mitigation is still considered more extensively during the initial "Identifying and Understanding" phase. This can be explained by the fact that European cities initially started addressing climate mitigation in their plans, often as a result of support from the Covenant of Mayors, but have only more recently started to address adaptation issues, either as stand-alone plans or in combined action plans such as the ones under investigation in this study. This also reflects the initial focus of the global climate policy processes and conventions (i.e. UNFCCC, Kyoto Protocol and Paris Agreement) on climate mitigation. The study shows that about $50 \%$ of European cities' combined CCAPs address adaptation and mitigation in a balanced way, including assessments of both GHG emissions and vulnerability profiles. However, when more technical assessments are needed (i.e. GHG emissions forecasts and climate projections), only one-quarter of CCAPs have included a more in-depth analysis for both adaptation and mitigation.

Although the cluster of high integrators is the smallest, there is a clear indication that CCAPs are advancing towards increased integration of adaptation and mitigation in France and the UK. The UK CCAPs scored highly in particular, with $82 \%$ 'moderate' and 'advanced' integrators, against $64 \%$ in France. As noted previously, CCAPs in both of these countries were produced in response to national regulation ${ }^{2}$ and national $\mathrm{CO}_{2}$ emissions reduction targets in $\mathrm{UK}^{3}$. This suggests that municipalities provided with clear policy guidance from national government, are able to better allocate resources that are necessary to undertake CCAPs with stronger integration. The study results are consistent with Reckien et al. [13, 49]. On the other hand in Germany, the new ministerial policy for local governments' management and funding (Gemeindeverordnung) recently decided that adaptation and mitigation should be treated separately, which might explain the low number of integrated urban climate change plans in Germany.

When focusing on the average level of UCCII in countries with 4-5 CCAPs, $63 \%$ of German, Finnish and Spanish CCAPs display a 'low' level of integration, while 37\% profile as 'moderate' integrators. Whilst this is evidence that progress is underway, more effort is still required at the local level to improve consideration of synergies and trade-offs between adaptation and mitigation. However, as this is not necessarily a simple task for urban managers, additional support should be provided in that direction either from the national government, via peer to peer learning in city networks or from partnering with other actors such as knowledge-based institutes. For example, the C40 have recently developed a

\footnotetext{
${ }^{2}$ In France, the law obliges municipalities with a population over 20,000 to develop local action plans

${ }^{3}$ The Climate Change Act
} 
qualitative assessment tool for identifying the interactions of adaptation and mitigation actions (The AMIA tool ${ }^{4}$ ).

\subsection{Interrelationships between mitigation and adaptation}

Out of the 147 cities combining both adaptation and mitigation policy objectives in their CCAPs, just over one quarter of them (38) explicitly consider Ad/Mit actions' synergies and co-benefits. Synergies and co-benefits were the type of interrelationships stated most frequently in specific sectors such as "Green Urban Infrastructure", "Construction, Energy efficiency and Buildings" and "Education and Communication", reinforcing the study results by Landauer et al [14] Demuzere et al [43] and others. However, this analysis shows that the case for evidence about mitigation and adaptation co-benefits is rarely backed up by any quantified assessment or consideration of target beneficiaries. Such tools include emissions forecasts, climate projections, climate mitigation targets, and risk assessments. These could be applied across the mitigation/adaptation fields to promote integration more proactively. A comprehensive review of assessment tools and benchmarking practices for cities can be found in Bose [44] and an application to achieve carbon reduction targets in London is reported by Villarroel et al [45].

Another observation from this analysis is that those CCAPs that focused on co-benefits and synergies did not identify conflicts or trade-offs between mitigation and adaptation. Yet within the breadth of sectors discussed in the CCAPs, negative interrelationships can be found [13], [14]. However, identifying trade-offs and conflicts requires technical capacity and is also time and resource consuming. Support and/or tools for decision support (including carbon impact and climate risk assessments), checklists, software, and guidelines could be provided to city officials to facilitate the identification and quantification of interrelationships within and between urban sectors. Support from national/ regional governments, city networks and research institutes may be critical in this area. Decision support tools for low carbon business planning for cities has come from the EU (The Smart Cities Information System, CommONEnergy, EU urban roadmaps tool), ICLEI (ClearPath ${ }^{\mathrm{TM}}$ ), European Commission (De-risking energy efficiency platform), World Bank (Curb tool), and academic institutions (Can Do Cities from the University of Leeds and CLIMACT Prio tool from Erasmus University Rotterdam). In addition, to the benefits of their technical capacity and access to resources, exploring conflicts may be easier for third parties who are often able to participate in a politically neutral way.

\subsection{Identifying gaps and needs in the different planning phases}

The analysis helps to identify capacity gaps and needs of local governments regarding integrated climate change planning. More specifically, with regard to the "Identifying and Understanding" phase, the results suggest that there are knowledge gaps and capacity development needs for technical assessments of future climate impacts and simultaneous analysis of GHG emissions and climate projections. Future climate projections can be used to inform adaptation policies in cities. As Bader et al. [46] note, it is important to establish a process where researchers and scientists provide current and future climate data and projections to urban policymakers. Although it can be quite challenging to relate climate

\footnotetext{
${ }^{4}$ https://resourcecentre.c40.org/resources/interaction-between-adaptation-and-mitigation-actions
} 
projections with cost damage estimates, Lenk et al. [47] note that decision-makers may only require an order of magnitude estimate of damage costs to inform many adaptation strategies.

The results of the study suggest that the main gaps and capacity development needs in the "Envisioning and Planning" stage are linked to the identification (and assessment) of Ad/Mit synergies, co-benefits, trade-offs and conflicts, along with the economic assessment of adaptation and mitigation actions during the prioritization process. The costs of implementing actions are often regarded as part of the decision making process. However, this analysis and results show this is not usually the case, which could be one of the reasons why climate change plans are often aspirational. In this regard, user-friendly tools and methodologies to support local governments in undertaking economic analysis need to be developed and become available to local governments. These would include, for example, cost-benefit analysis, abatement/adaptation cost analysis, or integrated approaches such as multi-criteria analysis. There are good international examples of cities that have applied such kind of methods to support their climate change action planning like Vancouver, New York, Mexico City and Durban to name a few. However, these are large cities with resources at their disposal.

It is often impractical for local governments to create new in-house capacity in some or all technical areas[44] such as those described in understanding and envisioning and planning phases. Instead, as recommended by Bai et al [48], they should build alliances with other cities, and work closely with local knowledge-based institutes and universities that can provide the necessary technical expertise, and look to city networks and urban NGOs who are increasingly providing examples of best practices that can be learned from. There are good examples of city-to-city alliances and peer-to-peer initiatives in Europe both in adaptation (City twinning programme of Mayors Adapt ${ }^{5}$ ) and mitigation (PROSPECT ${ }^{6}$ project funded by the EC) that could be replicated and upscaled addressing also mitigation and adaptation integration and interrelationships issues.

For the "Management and Implementation" phase, the results suggest that establishing a common funding body and securing finance for efficient integration of adaptation and mitigation are major issues that need to be addressed both by local and national governments. On the other hand, 84 CCAPs (57\%) have identified opportunities for mainstreaming mitigation and adaptation actions in specific sectoral plans and actions maximising the chances of finance from existing funds and ultimately implementation. Mainstreaming climate change mitigation and adaptation in existing plans could be an efficient way of addressing both policy objectives in a combined manner. However, this would require change in current planning practices.

\subsection{Limitations and future research}

The study found evidence that CCAPs stimulated by government directives result in higher $\mathrm{Ad} /$ Mit integration, but this is strongly influenced by the large number of plans that have been produced in the UK.

\footnotetext{
${ }^{5} \mathrm{https} / / /$ www.covenantofmayors.eu/IMG/pdf/CoM_TwinningsProgramme_infographic_final-HQ.pdf

${ }^{6}$ https://h2020prospect.eu/
} 
The cities under investigation vary considerably in their size, population, GDP etc. The relationship between $\mathrm{Ad} / \mathrm{Mit}$ integration, these and other variables should be explored in further work. For example the highest five scoring cities in terms of Ad/Mit integration have a population size ranging from 53,000 to 326,000 inhabitants, which may suggest that small to medium-sized cities recognise that an integrated approach is more cost-efficient considering the limited resources they have compared to larger cities. However, each city is a complex system characterized by different location, infrastructure, governance, resources and society, meaning that a statistical analysis would be required to determine any correlations.

The current analysis focuses on the integrated elements (e.g. interrelationships, common funding body) that have been identified in the CCAPs under investigation. Future work should identify potential challenges for integration especially consideration of $\mathrm{Ad} / \mathrm{Mit}$ challenges in the implementation phase. Investigation of the challenges and opportunities of $\mathrm{Ad} /$ Mit integration could, for example, involve conducting a survey among multiple local governments or in-depth interviews in cities identified as 'high integrators'. Another interesting research direction could explore how national governments mandate local governments to develop local CCAPs, particularly regarding the issue of Ad/Mit integration.

\section{Concluding remarks}

Managing both adaptation and mitigation in cities is urgent to tackle global climate change. Out of the 885 European municipalities' CCAPs that were analysed in a previous study [13], only 147 consider both adaptation and mitigation. This study applies a new index, the Urban Climate Change Integration Index, to assess the level of integration between adaptation and mitigation policy objectives in urban areas and to identify their synergies and co-benefits.

Looking at the 147 CCAPs, the analysis of countries with 4 to 5 CCAPs found the majority of plans to be 'early-stage' integrators and just over a third display a 'moderate' level of integration. The analysis of countries with 49 to 81 CCAPs, have a typically higher proportion of 'moderate' integrators and even a small number (3\%) of advanced 'integrators'. In this regard, the influence of national policies on local actions can explain why the highest scoring cities for level of integration are in France and the UK, where national regulations influence the advancements of their urban climate action planning. Less than half, $46 \%$, of the identified interrelationships refer to synergies between adaptation and mitigation actions, while $25 \%$ of interrelationships refer to mitigation actions with adaptation co-benefits. The sectors repeatedly identified as having the most synergies are "Green urban infrastructure" and "Construction, energy efficiency and buildings" highlighting the value of investment in these actions to prepare cities for climate change.

Local governments are making progress with the integration of combined approaches, but mitigation objectives remain more prominent than adaptation objectives despite repeated advice that must both be addressed [50]. All cities, both those following an integrated approach and those adopting a stand-alone approach in climate change planning, share similar issues in terms of the broad challenges of turning climate science into defined policies, actions and businesses cases. However, to maximise the multiple co-benefits and 
synergies of the integrated approach, additional capacities are needed in local governments, including additional technical capabilities.

The analysis exposes several barriers to the planning and implementation of integrated $\mathrm{Ad} /$ Mit approaches, shown in the low scores for questions that reveal technical capacities for quantitatively evaluating costs for integration of local governments, to develop emissions and climate vulnerability scenarios, and to implement common funding schemes. In this regard, national governments, cities' networks and partnerships have a critical role to play in guiding cities to identify adaptation-mitigation synergies, through consultation processes, technical support and awareness-raising. Better coordination among different levels of governance, for example through adopting a holistic mandate, can help cities to harness synergies and minimize trade-offs between adaptation and mitigation when they develop their urban climate change action plans. To understand these issues further, it is recommended augmenting this top-down analysis of high number of cities with in-depth interviews, surveys, and analysis of integrated mitigation-adaptation case studies.

\section{Acknowledgements}

Special thanks to Monica Salvia, Filomena Pietrapertosa, Sonia De Gregorio-Hurtado, Valentina D'Alonzo, Sofia G. Simoes, Eliska Krkoska Lorencova, Anja Wejs, Johannes Flacke, Marta Olazabal, Davide Geneletti, Efren Feliu, Sergiu Vasilie, Anna Krook-Riekkola, Marko Matosovic, Paris A. Fokaides, Byron I. Ioannou, Alexandros Flamos, Niki-Artemis Spyridaki, Mario V. Balzan, Orsolya Fülöp, Ivan Paspaldzhiev, who contributed to an initial database of local climate plans [7] that showed the existence of integrated mitigation and adaptation plans in European cities. In that respect, we also thank the EU COST Action TU0902, which helped to build a cross-European research network on local climate planning. The authors would also like to thank Sandra Valencia, Rory O'Brien, Anne Jegou and Lana Coste for their valuable support during the review of selected CCAPs. The authors are also grateful to three anonymous reviewers whose valuable comments have significantly improved the article.

\section{References}

[1] IPCC. Climate Change 2014: Mitigation of Climate Change: Working Group III Contribution to the IPCC Fifth Assessment Report. 2014. doi:10.1017/CBO9781107415416.

[2] Aguiar FC, Bentz J, Silva JMN, Fonseca AL, Swart R, Santos FD, et al. Adaptation to climate change at local level in Europe: An overview. Environ Sci Policy 2018. doi:10.1016/j.envsci.2018.04.010.

[3] Sullivan R, Gouldson A, Webber P. Erratum to Funding low carbon cities: Local perspectives on opportunities and risks. Clim Policy 2013:1-13.

doi:10.1080/14693062.2012.759698. 
[4] Global Covenant of Mayors [Internet]. 2018 [cited 2018 Dec 27]. Available from: www.globalcovenantofmayors.org

[5] Kongsager R, Locatelli B, Chazarin F. Addressing Climate Change Mitigation and Adaptation Together: A Global Assessment of Agriculture and Forestry Projects. Environ Manage 2016;57(2):271-282. doi:10.1007/s00267-015-0605-y.

[6] Gouldson A, Sudmant A, Khreis H, Papargyropoulou E. The Economic and Social Benefits of Low-Carbon Cities: A Systematic Review of the Evidence. Coalit Urban Transitions 2018. doi:10.1007/978-3-540-32210-8_6.

[7] Barnett J, O’Neill S. Maladaptation - Editorial. Glob Environ Chang 2010;2(20):211-213.

[8] Dawson RJ. Potential pitfalls on the transition to more sustainable cities and how they might be avoided. Carbon Manag 2011;2(2);175-188. doi:10.4155/cmt.11.8.

[9] Grafakos S, Pacteau C, Delgado M, Landauer M, Lucon O, Driscoll P. Integration of Climate Mitigation and Adaptation: Opportunities and Challenges. In: Rosenzweig C, Solecki W, Romero-Lankao P, Mehrotra S, Dhakal S, Ali Ibrahim S, editors. Climate Change and Cities: Second Assessment Report of the Urban Climate Change Research Network. New York: Cambridge University Press: 2018. p. 101-138.

[10] Landauer M, Juhola S, Söderholm M. Inter-relationships between adaptation and mitigation: a systematic literature review. Clim Change 2015;131:505-517. doi:10.1007/s10584-015-1395-1.

[11] Reckien D, Flacke J, Dawson RJ, Heidrich O, Olazabal M, Foley A, et al. Climate change response in Europe: What's the reality? Analysis of adaptation and mitigation plans from 200 urban areas in 11 countries. Clim Change 2014. doi:10.1007/s10584-013-0989-8.

[12] Aylett A. Institutionalizing the urban governance of climate change adaptation: Results of an international survey. Urban Clim 2015. doi:10.1016/j.uclim.2015.06.005.

[13] Reckien D, Salvia M, Heidrich O, Church JM, Pietrapertosa F, De Gregorio-Hurtado S, et al. How are cities planning to respond to climate change? Assessment of local climate plans from 885 cities in the EU-28. J Clean Prod 2018. doi:10.1016/j.jclepro.2018.03.220.

[14] Mendizabal M, Heidrich O, Feliu E, García-Blanco G, Mendizabal A. Stimulating urban transition and transformation to achieve sustainable and resilient cities. Renew Sustain Energy Rev 2018. doi:10.1016/j.rser.2018.06.003.

[15] Kane S, Shogren JF. Linking Adaptation and Mitigation in Climate Change Policy. In: Kane SM, Yohe GW, editors. Societal Adaptation to Climate Variability and Change.

Dordrecht: Springer; 2000. p. 75-102. Available from https://link.springer.com/chapter/10.1007/978-94-017-3010-5 6 
[16] Berry PM, Brown S, Chen M, Kontogianni A, Rowlands O, Simpson G, et al. Crosssectoral interactions of adaptation and mitigation measures. Clim Change 2014;128:381393. doi:10.1007/s10584-014-1214-0.

[17] Leonard S, Locatelli B, Murdiyarso D, Martius C, Quina M, Baral H. A match made in Paris: Adaptation-mitigation synergies in the land sector. 2016. doi:10.17528/cifor/006106.

[18] Klein RJT, Schipper ELF, Dessai S. Integrating mitigation and adaptation into climate and development policy: Three research questions. Environ Sci Policy 2005;8(6):579-588. doi:10.1016/j.envsci.2005.06.010.

[19] McEvoy D, Lindley S, Handley J. Adaptation and mitigation in urban areas: synergies and conflicts. Proc Inst Civ Eng - Munic Eng 2006;159(4):185-191.

doi:10.1680/muen.2006.159.4.185.

[20] Laukkonen J, Blanco PK, Lenhart J, Keiner M, Cavric B, Kinuthia-Njenga C. Combining climate change adaptation and mitigation measures at the local level. Habitat Int 2009;33(3): 287-292. doi:10.1016/j.habitatint.2008.10.003.

[21] Wilby RL. A review of climate change impacts on the built environment. Built Environ 2007;33(1): 31-45. doi:10.2148/benv.33.1.31.

[22] Gasper R, Blohm A, Ruth M. Social and economic impacts of climate change on the urban environment. Curr Opin Environ Sustain 2011;3(3):150-157.

doi:10.1016/j.cosust.2010.12.009.

[23] Hunt A, Watkiss $P$. Climate change impacts and adaptation in cities: $A$ review of the literature. Clim Change 2011;104(1):13-49. doi:10.1007/s10584-010-9975-6.

[24] Zimmerman R, Faris C. Climate change mitigation and adaptation in North American cities. Curr Opin Environ Sustain 2011;3(3):181-187. doi:10.1016/j.cosust.2010.12.004.

[25] Bassett E, Shandas V. Innovation and Climate Action Planning. J Am Plan Assoc 2010;76(4):435-450. doi:10.1080/01944363.2010.509703.

[26] Carter JG. Climate change adaptation in European cities. Curr Opin Environ Sustain 2011;3(3):193-198. doi:10.1016/j.cosust.2010.12.015.

[27] Orru K, Tillmann M, Ebi KL, Orru H. Making administrative systems adaptive to emerging climate change-related health effects: Case of Estonia. Atmosphere (Basel) 2018;9(6). doi:10.3390/atmos9060221.

[28] ICLEI [Internet]. Our network; 2018 [cited 2018 December 05]. Available from https://iclei.org/en/our network.html

[29] C40 Cities [Internet]. C40 Cities, 2018. Available from https://www.c40.org/ 
[30] EU Covenant of Mayor for Climate and Energy [Internet]. Covenant initiatives: Covenant in Figures; 2018. Available from https://www.covenantofmayors.eu/about/covenantinitiative/covenant-in-figures.html

[31] The Rockefeller Foundation [Internet]. Promoting the well-being of humanity throughout the world. Available from https://www.rockefellerfoundation.org/

[32] Croci E, Lucchitta B, Janssens-Maenhout G, Martelli S, Molteni T. Urban CO2 mitigation strategies under the Covenant of Mayors: An assessment of 124 European cities. J Clean Prod 2017;169:161-177. doi:10.1016/j.jclepro.2017.05.165.

[33] Heidrich O, Dawson RJ, Reckien D, Walsh CL. Assessment of the climate preparedness of 30 urban areas in the UK. Clim Change 2013;120(4):771-784. doi:10.1007/s10584-0130846-9.

[34] Araos M, Berrang-Ford L, Ford JD, Austin SE, Biesbroek R, Lesnikowski A. Climate change adaptation planning in large cities: A systematic global assessment. Environ Sci Policy 2016;66:375-382. doi:10.1016/j.envsci.2016.06.009.

[35] Caparros-Midwood D, Dawson RJ, Barr S (2019) Low Carbon, Low Risk, Low Density: Resolving choices about sustainable development in cities, Cities, 89: 252-267 (doi: 10.1016/j.cities.2019.02.018).

[36] Hansen R, Frantzeskaki N, McPhearson T, Rall E, Kabisch N, Kaczorowska A, et al. The uptake of the ecosystem services concept in planning discourses of European and American cities. Ecosyst Serv 2015;12:228-246. doi:10.1016/j.ecoser.2014.11.013.

[37] Geneletti D, Zardo L. Ecosystem-based adaptation in cities: An analysis of European urban climate adaptation plans. Land Use Policy 2016;50:38-47.

doi:10.1016/j.landusepol.2015.09.003.

[38] Bosello F, Carraro C, De Cian E. Climate Policy and the Optimal Balance between Mitigation, Adaptation and Unavoided Damage. 2010;1(2):71-92. doi:10.2139/ssrn.1594636.

[39] Ayers JM, Huq S. The value of linking mitigation and adaptation: A case study of Bangladesh. Environ Manage 2009;43(5):753-764. doi:10.1007/s00267-008-9223-2.

[40] Biesbroek GR, Swart RJ, van der Knaap WGM. The mitigation-adaptation dichotomy and the role of spatial planning. Habitat Int 2009;33(3):230-237.

doi:10.1016/j.habitatint.2008.10.001.

[41] Grafakos S, Trigg K, Landauer M, Chelleri L, Dhakal S. Analytical framework to evaluate the level of integration of climate adaptation and mitigation in cities, Clim Change 2019;1-20. doi:10.1007/s10584-019-02394-w.

[42] Tol RSJ. Adaptation and mitigation: Trade-offs in substance and methods. Environ Sci Policy 2005;8(6):572-578. doi:10.1016/j.envsci.2005.06.011. 
[43] Demuzere M, Orru K, Heidrich O, Olazabal E, Geneletti D, Orru H, et al. Mitigating and adapting to climate change: Multi-functional and multi-scale assessment of green urban infrastructure. J Environ Manage 2014;146:107-115 . doi:10.1016/j.jenvman.2014.07.025.

[44] Bose RK. Energy Efficient Cities: Assessment Tools and Benchmarking Practices. 2010. doi:10.1596/978-0-8213-8104-5.

[45] Villarroel Walker R, Beck MB, Hall JW, Dawson RJ, Heidrich O. Identifying key technology and policy strategies for sustainable cities: A case study of London. Environ Dev 2017;21:1-18. doi:10.1016/j.envdev.2016.11.006.

[46] Bader D, Blake R, Grimm A, Hamdi R, Kim Y, Horton R, Rosenzweig C. In: Rosenzweig C, Solecki W, Romero-Lankao P, Mehrotra S, Dhakal S, Ali Ibrahim S, editors. Climate Change and Cities: Second Assessment Report of the Urban Climate Change Research Network. New York: Cambridge University Press: 2018. p. 27-60.

[47] Lenk S, Rybski D, Heidrich O, Dawson RJ, Kropp JP. Costs of sea dikes-regressions and uncertainty estimates. Nat Hazards Earth Syst Sci 2017;17(5):765-779.

doi:10.5194/nhess-17-765-2017.

[48] Bai X, Dawson RJ, Ürge-Vorsatz D, Delgado GC, Salisu Barau A, Dhakal S, et al. Six research priorities for cities and climate change. Nature 2018;555:23-25.

doi:10.1038/d41586-018-02409-z.

[49] Reckien D, Salvia M, Pietrapertosa F, Simoes SG, Olazabal M, De Gregorio Hurtado S, Geneletti D, Krkoška Lorencová E, D'Alonzo V, Krook-Riekkola A, Fokaides PA, loannou BI, Foley A, Orru H, Orru K, Wejs A, Flacke J, Church JM, Feliu E, Vasilie S, Nador C, Matosović M, Flamos A, Spyridaki N-A, Balzan MV, Fülöp O, Grafakos S, Paspaldzhiev I, Heidrich O (2019): Dedicated versus mainstreaming approaches in local climate plans in Europe. Renewable and Sustainable Energy Reviews 112: 948-959.

https://doi.org/10.1016/j.rser.2019.05.014

[50] CCC, (2019), Progress in preparing for climate change - 2019 Progress Report to Parliament, Committee on Climate Change, London, UK.

https://www.theccc.org.uk/publication/progress-in-preparing-for-climate-change-2019progress-report-to-parliament/

Appendix 1: Scoring system

Scoring system related to GHG Emissions Forecast

Score $\quad$ Status 
Journal Pre-proof

\begin{tabular}{|c|c|}
\hline 0 & CCAP does not contain a GHG emission forecast. \\
\hline 1 & CCAP provides future GHG emissions forecast (up to 2020). \\
\hline 2 & CCAP contains a forecast of GHG emissions forecast (beyond 2020). \\
\hline \multicolumn{2}{|c|}{ Scoring system related to Vulnerability Profile } \\
\hline Score & Status \\
\hline 0 & CCAP does not mention any vulnerabilities that the city will face. \\
\hline 1 & $\begin{array}{l}\text { CCAP suggests that a vulnerability profile has been completed but its data is not } \\
\text { stated within the plan. OR } \\
\text { CCAP mentions some vulnerability issues for the city, but does not provide a } \\
\text { concise overview. }\end{array}$ \\
\hline 2 & CCAP contains a full vulnerability profile of the city. \\
\hline \multicolumn{2}{|c|}{ Scoring system related to Future Climate Projections } \\
\hline Score & Status \\
\hline 0 & CCAP does not mention any future climate projections for the city. \\
\hline 1 & CCAP provides future climate projections in the short-term (up to 2020). \\
\hline 2 & CCAP provides future climate projections in the long-term (up to 2050). \\
\hline \multicolumn{2}{|c|}{ Scoring system related to GHG emissions reductions target } \\
\hline Score & Status \\
\hline 0 & CCAP does not provide a GHG emissions reduction target. \\
\hline 1 & CCAP provides reductions target in the short-term (up to 2020). \\
\hline 2 & CCAP provides reductions target in the long-term (up to 2050). \\
\hline \multicolumn{2}{|c|}{ Scoring system related to Adaptation Objectives } \\
\hline
\end{tabular}




\begin{tabular}{|c|c|}
\hline Score & Status \\
\hline 0 & CCAP does not state any adaptation objective. \\
\hline 1 & $\begin{array}{l}\text { CCAP contains adaptation objectives in the short term (up to } 5 \text { years). OR } \\
\text { CCAP mentions adaptation objectives without specific timescale. }\end{array}$ \\
\hline 2 & CCAP contains adaptation objectives in the long term (more than 5 years). \\
\hline \multicolumn{2}{|c|}{ Scoring system related to Cost estimates of actions } \\
\hline Score & Status \\
\hline 0 & CCAP does not include any cost estimate of proposed actions. \\
\hline 1 & CCAP provides cost estimates of either adaptation or mitigation actions. \\
\hline 2 & CCAP provides cost estimates of both adaptation or mitigation actions. \\
\hline \multicolumn{2}{|c|}{ Scoring system related to Benefit estimates of actions } \\
\hline Score & Status \\
\hline 0 & CCAP does not include any benefit estimate of proposed actions. \\
\hline 1 & CCAP provides benefit estimates of either adaptation or mitigation actions. \\
\hline 2 & CCAP provides benefit estimates of both adaptation or mitigation actions. \\
\hline \multicolumn{2}{|c|}{$\begin{array}{l}\text { Scoring system related to Consideration of Ad/Mit interrelationships (co- } \\
\text { benefits/synergies or trade-offs/conflicts) }\end{array}$} \\
\hline Score & Status \\
\hline 0 & CCAP does not include any interrelationship of adaptation and mitigation. \\
\hline 1 & CCAP provides either synergies or conflicts of adaptation and mitigation. \\
\hline 2 & CCAP provides both synergies and conflicts of adaptation and mitigation. \\
\hline
\end{tabular}




\begin{tabular}{|c|c|}
\hline \multicolumn{2}{|c|}{ Scoring system related to Mainstream potential of climate actions } \\
\hline 0 & CCAP does not include any mainstreaming potential of climate actions. \\
\hline 1 & CCAP mentions mainstreaming potential of either adaptation or mitigation. \\
\hline 2 & CCAP mentions mainstreaming potential of both adaptation and mitigation. \\
\hline \multicolumn{2}{|c|}{ Scoring system related to Common policy or regulatory framework } \\
\hline 0 & CCAP does not include any policy or regulatory framework. \\
\hline 1 & $\begin{array}{l}\text { CCAP mentions policy or regulatory framework regarding either adaptation or } \\
\text { mitigation. }\end{array}$ \\
\hline 2 & $\begin{array}{l}\text { CCAP mentions policy or regulatory framework addressing both adaptation and } \\
\text { mitigation. }\end{array}$ \\
\hline \multicolumn{2}{|c|}{ Scoring system related to Partnerships } \\
\hline 0 & CCAP does not include any partnership possibility. \\
\hline 1 & CCAP mentions partnerships regarding either adaptation or mitigation. \\
\hline 2 & CCAP mentions partnerships regarding both adaptation and mitigation. \\
\hline \multicolumn{2}{|c|}{ Scoring system related to Common Monitoring procedure/ framework } \\
\hline 0 & CCAP does not include monitoring procedure/framework. \\
\hline 1 & $\begin{array}{l}\text { CCAP mentions a monitoring procedure/framework regarding either adaptation } \\
\text { or mitigation. }\end{array}$ \\
\hline 2 & $\begin{array}{l}\text { CCAP mentions a monitoring procedure/framework regarding both adaptation } \\
\text { and mitigation. }\end{array}$ \\
\hline
\end{tabular}

\section{Appendix 2: Guidelines for reviewing and analyzing CCAPs}

I) Identifying and Understanding stage

Scientific knowledge and information 
1) GHG emissions profile: Identify whether the CCAP has included GHG profile or inventory that show quantitative summary of most representative data of the city's GHG emissions as well as an adequate sectoral breakdown at both community and government level. Related keywords might be GHG emissions profile, GHG emissions inventory, GHG emission levels, etc.

i) If GHG profile was identified in the plan $\rightarrow$ Score 1

ii) If GHG emissions profile was not included in the plan $\rightarrow$ Score 0

$>$ Example in Durban's plan, "The total amount of greenhouse gas emissions recorded for the entire city was 29,360,395 tCO2e. Total emissions are estimated to have increased steadily from 19,937,000 tCO2e in 2002 (a 47\% increase over 10 years)" and "Durban's GHG Inventory is divided into two sub-inventories, one for the local government emissions, and the other for the emissions from the broader community" and the sectoral breakdown of GHG emissions was provided in the form of pie chart

2) GHG Emissions Forecast (with time horizon): identify whether the CCAP has provided future GHG emissions forecasts in the form of text or chart (graph) that include a consideration of the city's current and projected growth of GHG emission, you will score this variable depending on the time horizon. Related keywords might be GHG emissions, path, forecast, prospect, projection, etc.

i) If GHG emission forecast was estimated beyond $\mathbf{2 0 2 0} \rightarrow$ Score 2

ii) If GHG emission forecast was estimated up to $2020 \rightarrow$ Score 1

iii) If GHG emission forecast was not included in the plan $\rightarrow$ Score $\mathbf{0}$

$>$ Example from Chicago's plan, "If Chicago continues on its current path, just like many other cities, its greenhouse gas emissions could increase 35 percent by the year 2050' with a graph illustrating the city's GHG emission forecast upto 2050 (p.14) $\rightarrow$ Score 2

3) Vulnerability Profile: search whether the plan has provided the city's vulnerability profile that consider climate change impacts by considering vulnerability factors such as exposure, sensitivity, and adaptive capacity into account. In many cases the vulnerability profile has the form of a Vulnerability Assessment, Vulnerability mapping, Climate Risk assessment and mapping. Related keywords are vulnerability profile, vulnerable areas, hazard map, risk/impact assessment, etc.

i) If vulnerability profile/assessment was supported by quantitative data $\rightarrow$ Score 2

ii) If vulnerability profile/assessment was described but without quantitative data $\rightarrow$ Score 1

iii) If vulnerability profile/assessment was not included in the plan $\rightarrow$ Score $\mathbf{0}$

$>$ Example from Paris's plan, "the Vulnerability and strength of Paris in the face of climate change and the scarcity of resources" was completed separately and is used as a basis for creating the adaptation strategy for Paris. $\rightarrow$ Descriptive vulnerability assessment without quantitative data $\rightarrow$ Score 1

$>$ Example from Vancouver Plan: "Vulnerability and risk assessment details" were presented in Appendix B $\rightarrow$ Specific vulnerability assessment in terms of different climate impacts was provided to help identifying vulnerable areas and prioritizing relevant climate actions

Score

4) Future Climate Projections: identify whether the plan has included climate projections in the form of text/graph that indicate projected changes of the city climate. Related keywords might include expected changes in climate, temperature, 
extreme weather events, sea level rise, precipitation, rainfall, etc. You will score the variable depending on the time horizon of the projection.

i) If climate projection was set up beyond $\mathbf{2 0 3 0} \rightarrow$ Score 2

ii) If climate projection was set up to $\mathbf{2 0 3 0}$ (or no specific time scale) $\rightarrow$ Score $\mathbf{1}$

iii) If future climate projection was not included in the plan $\rightarrow$ Score $\mathbf{0}$

$>$ Example from Durban's plan, "The average annual temperature increase is expected to be between $1.5 \mathrm{C}$ and $2.5^{\circ} \mathrm{C}$ by 2065 , and increase between $3^{\circ} \mathrm{C}$ and $5^{\circ} \mathrm{C}$ by 2100." "Potential increase in aggregate rainfall by 2065 with an increase of up to 500 $\mathrm{mm}$

Score

5) Both GHG emissions and Vulnerability Profiles: This variable combines variables 1) and 3), illustrating if the city plan includes both GHG emissions and vulnerability profiles

6) Both Emissions Forecast and Climate Projections: This variable combines variables 2) and 4), illustrating if the city plan includes both GHG emissions and future climate projections

$>$ Variables 5) and 6) are designed to get scores automatically in the final excel spreadsheet, please continue to the next item directly.

7) Uncertainty of climate impacts: identify whether the plan has suggested how to address uncertainties of climate impacts. The estimates of uncertainties are statements intended to describe the limits to knowledge. The IPCC notes that "uncertainties can be classified between levels of confidence in scientific understanding (structural uncertainties), and the likelihoods of specific results (value uncertainties). Related keywords might include uncertainties, probabilities, likelihoods, scenarios of (climate impacts).

i) If uncertainty of climate impacts was addressed in the plan $\rightarrow$ Score 1

ii) If uncertainty of climate impacts was not included in the plan $\rightarrow$ Score $\mathbf{0}$

8) Cost estimates of damages of climate impacts: identify whether the plan has included economic cost estimates of damages (that could be) caused by climate impacts. Related keywords might include costs, value at risk, economic damages, GDP losses, etc.

i) If cost estimates of damages were indicated in the plan $\rightarrow$ Score 1

ii) If cost estimates of damages were not included in the plan $\rightarrow$ Score 0

$>$ Example from Vancouver's plan, "The National Round Table on the Environment and the Economy (NRTEE) found that world-wide greenhouse gas emissions and subsequent climate change impacts could, in turn, have an economic impact on Canada of $\$ 5$ billion annually by 2020 and between $\$ 21$ and $\$ 43$ billion annually by 2050. Specific to BC by the 2050s, timber supply impacts could range from $\$ 2$ billion to $\$ 17$ billion annually and flooding damages to coastal dwellings could cost between $\$ 1$ billion to $\$ 8$ billion per year." $(p .17) \rightarrow$ Score 1

9) Climate Hazards detailed: identify whether the CCAP has suggested specific types of climate hazards that the city might face as a result of climate change. Related keywords might include: droughts, storms, floods, extreme weather events, heat waves, sea level rise, etc.

i) If relevant climate hazards were detailed in the plan $\rightarrow$ Score $\mathbf{1}$

ii) If relevant climate hazards were not detailed in the plan $\rightarrow$ Score $\mathbf{0}$

$>$ Example from Durban "Durban is projected to experience an increase in the frequency and intensity of extreme weather events, including flash floods, droughts, 
and an increase in the number and severity of coastal storms - which will be exacerbated by sea level rise." (p.5) $\rightarrow$ Score 1

II) Envisioning and planning stage

Target setting

1) GHG emissions reduction targets: check whether the plan has set out city-level GHG emission reductions targets with time horizon, if so, score the variable based on the timescale of the targets. Related keywords might include GHG emission reduction, goals, targets, etc.

i) If GHG emissions reduction targets were specified and set by $\mathbf{2 0 5 0} \rightarrow$ Score 2

ii) If GHG emissions reduction targets were specified and set by $\mathbf{2 0 2 0} \rightarrow$ Score $\mathbf{1}$

iii) If GHG emissions reduction targets were not included in the plan $\rightarrow$ Score $\mathbf{0}$

$>$ Example from Chicago "Chicago needs to achieve an 80 percent reduction below 1990 GHG emissions level by the year 2050 in order to do its part to avoid the worst global impacts of climate change." (p.14) $\rightarrow$ Score 2

2) GHG emissions reduction sectoral targets : assess whether the city's total GHG emissions reduction targets were broke down into different sectors that should be responsible for GHG emissions reductions. Related keywords are sectors (e.g. transportation, buildings, energy, waste, urban green, etc), sectoral emissions, etc.

i) If sectoral GHG reduction targets were identified $\rightarrow$ Score $\mathbf{1}$

ii) If sectral target for GHG emissions reductions was not included in the plan $\rightarrow$ Score $\mathbf{0}$

$>$ Example from Chicago's plan, the city's total GHG reductions were broke down into sectoral targets, for such as "Mitigation actions in Energy Efficient Buildings will contribute to 30\% of total Chicago GHG Reductions" $\rightarrow \quad$ Score 1

3) Adaptation Objectives: identify whether the plan has included a set of adaptation objectives in order to cope with most pressing climate impacts for the city. Climate change adaptation refers to "The process of adjustment to actual or expected climate and its effects. In human systems, adaptation seeks to moderate harm or exploit beneficial opportunities. In natural systems, human intervention may facilitate adjustment to expected climate and its effects." (IPCC, 2013:3). Related keywords might include adaptation objectives, strategies, goals, etc.

i) If adaptation objectives were identified with long term timescale (more than 5 years) $\rightarrow$ Score 2

ii) If adaptation objectives were identified with short term timescale (up to 5 years) or without specific time scale $\rightarrow$ Score 1

iii) If adaptation objective was not included in the plan $\rightarrow$ Score $\mathbf{0}$

$>$ Example from Paris's plan: chapter "An Adaptation Strategy", a series of adaptation actions were set out in response to the climate impacts that are increasingly affecting the city, such as "Heatwaves, urban heat islands effects; Floods, droughts, drinkability, cooling: water and adaptation.", however, the plan did not include time scale for proposed adaptation objectives $\rightarrow$ score 1

$>$ Example from Bangkok's plan: according to the time scale of the main climate impacts in the city (flooding, coastal erosion, drought and saline intrusion), Bangkok will take short term (1-3 years), midterm (3-5 years) and long term (5-10 years) of actions, to prevent, minimize impacts, then change and construct infrastructures. $\rightarrow$ score 
4) Consideration of both GHG reduction targets and adaptation objectives: determined by whether the plan has included both GHG reduction targets and adaptation objectives.

$>$ Variable 4) will be designed to get scores automatically in the final excel spreadsheet, please continue to the next item directly.

Prioritization

1) Cost estimates of actions: check whether the plan has included cost estimates of implementation of proposed Ad/Mit actions, Related keywords might be cost, estimates, investment costs, project costs, etc. You will score the variable based on the contents of the estimation.

i) If costs were estimated for both Ad and Mit actions $\rightarrow$ Score 2

ii) If costs were estimated for either Ad or Mit actions $\rightarrow$ Score $\mathbf{1}$

iii) If cost estimate of actions was not included in the plan $\rightarrow$ Score $\mathbf{0}$

$>$ Example from Seoul's plan: cost estimates of project implementation by sector were included in chapter "financial plans and administration" through a summary table.

Total Project Cost (2015 - 2020): Approx. KRW 13.6630 trillion

\begin{tabular}{|c|r|r|r|r|r|r|r|}
\hline Sector & \multicolumn{1}{c|}{ Total } & \multicolumn{1}{c|}{$\mathbf{2 0 1 5}$} & \multicolumn{1}{c|}{$\mathbf{2 0 1 6}$} & \multicolumn{1}{c|}{$\mathbf{2 0 1 7}$} & \multicolumn{1}{c|}{$\mathbf{2 0 1 8}$} & $\mathbf{2 0 1 9}$ & \multicolumn{1}{c|}{$\mathbf{2 0 2 0}$} \\
\hline Total & $13,663,064$ & $1,776,779$ & $2,234,503$ & $2,336,021$ & $2,578,585$ & $2,335,823$ & $2,401,353$ \\
\hline Energy & $2,126,589$ & 294,306 & 369,921 & 385,176 & 372,160 & 351,195 & 353,831 \\
\hline $\begin{array}{c}\text { Air and } \\
\text { Transport }\end{array}$ & $6,162,207$ & 709,492 & 819,916 & 973,916 & $1,279,915$ & $1,168,216$ & $1,210,752$ \\
\hline $\begin{array}{c}\text { Resource } \\
\text { Circulation }\end{array}$ & $1,490,613$ & 157,411 & 238,673 & 173,749 & 199,796 & 357,720 & 363,264 \\
\hline Ecology & 801,815 & 115,124 & 110,429 & 127,181 & 141,138 & 146,873 & 161,070 \\
\hline $\begin{array}{c}\text { Health and } \\
\text { Safety }\end{array}$ & $3,081,840$ & 500,446 & 695,564 & 675,999 & 585,576 & 311,819 & 312,436 \\
\hline
\end{tabular}

Cost estimates of sectoral projects that can be considered as either Ad or Mit actions $\rightarrow$ Score 1

2) Benefit estimates of actions: check whether the plan has recognized and estimated economic (individual or public) benefits of proposed actions. Related keywords might include benefits, profits, paybacks, savings, revenues, etc.

i) If benefit were estimated for both Ad and Mit actions $\rightarrow$ Score 2

ii) If benefits were estimated for either Ad or Mit actions $\rightarrow$ Score $\mathbf{1}$

iii) If benefit estimate of action was not included in the plan $\rightarrow$ Score $\mathbf{0}$

$>$ Example from Chicago's plan, “Huge personal savings come from switching to public transportation-as much as $\$ 400$ a month when totalling fuel costs, insurance and parking."

"the city has retrofitted 15 million square feet of its office space, saving $\$ 6,000,000$ on energy costs"( $p .17) \rightarrow$ benefit estimates were made only for Mit actions $\rightarrow$ Score 1

3) Consideration of Ad/Mit interrelationships: identify whether the plan has suggested the interrelationships of $\mathrm{Ad}$ and Mit actions during the Prioritization process. Related keywords: interrelationships, co-benefits, trade-offs, conflicts, cross-cutting, mutual benefits, etc. In cases that none of these keywords are stated, but there is a clear description of an Ad/Mit synergy, co-benefit or conflict, then the CCAP considers Ad/Mit interrelationships.

For instance if a climate action (e.g. green roofs) is described in a CCAP as an action that will reduce the need for energy for cooling (mitigation) and also the rainwater runoff during intense rainfall (adaptation), then we consider that the CCAP states $\mathrm{Ad} /$ Mit interrelationships (in this example synergy), even without using the word synergy or co-benefit. 
Interrelationships of Ad and Mit - conflict, trade-off, co-benefit

Climate Ad and Mit actions are interrelated- in some cases positively (synergies), in others negatively (conflicts) - and sometimes decisions on implementation are based on difficult tradeoffs. A conflict is a plan, policy, or measure that counteracts or undermines one or more planning goals between adaptation and mitigation. A co-benefit occurs when a plan, policy or measure that aims to enhance an adaptation (mitigation) objective, leads simultaneously to the enhancement of mitigation (adaptation) objective. On the contrast, a trade-off is a situation that necessitates choosing (balancing) between one or more desirable, but sometimes conflicting, plans, policies, or measures.

i) If both synergies and conflicts of $\mathrm{Ad} /$ Mit were identified $\rightarrow$ Score 2

ii) If either synergies or conflicts of Ad/Mit were identified $\rightarrow$ Score 1

iii) If interrelationship of Ad and Mit actions was not included in the plan $\rightarrow$ Score $\mathbf{0}$

$>$ Example from Vancouver's plan (co-benefit) "Mitigation and adaptation are not mutually exclusive, with many actions contributing to both goals. Examples include water conservation and effective building envelopes which reduce GHGs now, but also mitigate the effects of extended hotter, drier weather in the future." (p.4) $\rightarrow$ Score 1

4) Sustainability benefits: Check whether the plan has stated sustainability benefits that were generated (directly or indirectly) by the proposed adaptation or mitigation actions, apart from the identified co-benefits of Ad and/or Mit actions. Related keywords: sustainability co-benefits, quality of life, jobs creation, water quality, human health, etc. i) If sustainability benefits were suggested $\rightarrow$ Score 1 ii) If sustainability benefit was not included in the plan $\rightarrow$ Score $\mathbf{0}$

$>$ Example from Chicago's plan, "Extra benefits: beyond averting changes to our climate, these actions have the potential to offer many other important benefits. Thousands of jobs may be created annually once the actions are underway.

\section{Communication}

1) Common public education and outreach: identify whether the plan has included actions that aiming at enhancing public knowledge regarding both $\mathrm{Ad}$ and Mit. Related keywords might include education, awareness, knowledge, campaigns, etc.

i) If public education and outreach for both Ad and Mit actions were identified $\rightarrow$ Score 1

ii) If common public education and outreach was not included in the plan $\rightarrow$ Score $\mathbf{0}$

$>$ Example from Durban's plan, stated "Develop a range of audience-appropriate and innovative education and awareness resources to explain climate change, its potential impact on Durban, methods of reducing GHG emissions and how to adapt to changing conditions." (p.44) $\rightarrow$ Score 1

III) Implementation, management and monitoring stage

Financing

1) Common Funding Body or Budget: check whether the plan has suggested a common source (national/city level) of funding body or budget to finance both Mit and Ad actions. Related keywords might be (usually with "climate" in the name) financing, funding, budget, etc.

i) If a common funding body was identified $\rightarrow$ Score 1

ii) If common funding body/budget was not included in the plan $\rightarrow$ Score $\mathbf{0}$ 
$>$ Example from Wellington's plan: "Since 2010-2011, the council has allocated funding to specific measures in the Climate Change Action Plan." $\rightarrow$ Score 1

$>$ Example from Montevideo's CCAP: each department should start working on the short-term projects with its budget $\rightarrow$ Score 0

2) Financing commitment: identify whether implementation of some (or all) proposed actions were financially secured with clear financing sources, regardless public or private. Related keywords might be budgeting, funding source, subsidies, grants, financial incentives, etc.

i) If financing commitments of proposed actions were identified $\rightarrow$ Score $\mathbf{1}$

ii) If financing commitment was not included in the plan $\rightarrow$ Score $\mathbf{0}$

$>$ Example from Seoul's plan: specific budgeting of proposed climate actions in different sectors (including energy, air and transport, resource circulation, ecology, health and safety) has been included in the Appendix 2. $\rightarrow$ Score 1

Implementation

1) Mainstreaming potential of $\mathrm{Ad} / \mathrm{Mit}$ actions: examine whether potentials of mainstreaming climate actions were considered in the plan. In the context of climate change, mainstreaming refers to the incorporation of climate change considerations into established or on-going development programs, policies or management strategies, rather than developing adaptation and mitigation initiatives separately. Related keywords are mainstreaming, incorporating, integration, etc.

i) If mainstreaming was suggested for both Ad and Mit actions $\rightarrow$ Score 2

ii) If mainstreaming was suggested for either Ad or Mit actions $\rightarrow$ Score $\mathbf{1}$

iii) If mainstreaming potential was not included in the plan $\rightarrow$ Score $\mathbf{0}$

$>$ Example from Wellington's plan, "reducing emissions through an update of the Wellington transport strategy (mitigation)" and "The Climate Change Action Plan now falls within the scope of Our Living City so it can be integrated with other Council projects (adaptation)" $\rightarrow$ Mainstreaming was discussed in Both Ad and Mit actions $\rightarrow$ Score 2

3) Common Policy or Regulatory Framework: identify whether the plan has mentioned a common policy or regulatory framework that provides guidance and requirements of climate change planning and implementation for both Mit and $\mathrm{Ad}$ actions. Related keywords might be policy, regulatory framework, law, etc. i) If a common policy/framework regarding both Ad and Mit actions was identified $\rightarrow$ Score 2

ii) If policies/regulatory frameworks regarding either Ad or Mit actions were identified $\rightarrow$ Score 1

Score 0

iii) If policy or regulatory framework for climate actions was not included in the plan $\rightarrow$

> Example from Wellington's plan, "The New Zealand Emissions Trading Scheme (NZ ETS), which came into force in 2008, is New Zealand's primary climate change measure.... Wellington City Council and other entities in the city with obligations must comply with the NZ ETS." (Mitigation) $\rightarrow$ Score 1

4) Common coordination/implementation body: identify whether there was an established body/department (or an institutional arrangement) responsible for the coordination and/or the implementation of climate actions, including both Mit and Ad. Otherwise it was for various entities (departments) individually to carry out relevant 
actions without a central coordination. Related keywords are (often with "climate" in the name) committee, division, department ; coordination, planning, etc.

i) If a common coordination/implementation body was identified $\rightarrow$ Score 1

ii) If a common coordination/implementation body was not included in the plan $\rightarrow$ Score $\mathbf{0}$

$>$ Example from Bangkok's plan: the city council will establish and strengthen institutional arrangement to design and implement the Master Plan (with a graph to illustrate the institutional arrangement, where the "Steering Committee" provides overall guidance and coordination to ensure consistency and integration of work across different task forces (transport, energy, waste wastewater, urban greening, adaptation) $\rightarrow$ Score 1

4) Partnerships: identify whether the plan has stated the use of partnerships (public private, local - other government, local government - civil society, etc.) to support the implementation of both adaptation and mitigation, for example, public-privatepartnerships assist realisation of climate actions through the committed financial support provided by private sector. Related keywords are partnerships, civil society, public-private,

etc.

i) If the use of partnerships was identified for both Ad and Mit actions $\rightarrow$ Score 2

ii) If the use of partnerships was identified for either Ad or Mit actions $\rightarrow$ Score 1

ii) If partnership was not included in the plan $\rightarrow$ Score 0

$>$ Example from Vancouver's plan, "In order to incorporate adaptation considerations in City business, there shall be several levels of partnerships formed; (a) Public - private whereby the city shall partner with private entities...(b) Local - other government..." $\rightarrow$ Score 1

$>$ Example from Bangkok's plan "BMA in partnership with the national government ministries and agencies, takes a major responsibility to mitigate and adapt to climate

change"

$\rightarrow \quad$ Score

Monitoring

1) Common Monitoring system: check whether there was a common monitoring system or committee to review the performance of both Ad/Mit climate actions, allowing revisions and improvements through feedback mechanisms. Related keywords are monitoring system, evaluation, reporting, review, committee, revisions, adjustments, etc.

i) If a common monitoring system was identified for both Mit and Ad actions $\rightarrow$ Score 2

ii) If a monitoring system was identified for either Mit or Ad actions $\rightarrow$ Score $\mathbf{1}$

iii) If climate action monitoring system was not included in the plan $\rightarrow$ Score $\mathbf{0}$

$>$ Example from Wellington's plan, "the council will monitor the development of climate change mitigation measures" $\rightarrow$ Score 1

$>$ Example from Paris' plan, "Aware of these future changes, back in 2007 the Council of Paris decided that the Climate Action Plan should be updated every five years. As a result, it set up a Climate Action Plan monitoring committee" $\rightarrow$ Score 2 
Appendix 3: List of all cities' CCAPs scores in descending order and divided per level of integration

\begin{tabular}{|c|c|c|c|c|c|}
\hline city & country & $\begin{array}{l}\text { Idontifying and } \\
\text { Understanding } \\
\text { Scoro }\end{array}$ & $\begin{array}{l}\text { Envision and } \\
\text { Planning } \\
\text { Score }\end{array}$ & $\begin{array}{l}\text { Implomenlation and } \\
\text { Monilo ring Scom }\end{array}$ & $\begin{array}{l}\text { Total } \\
\text { Scoro }\end{array}$ \\
\hline Scuthampion & $\mathrm{UK}$ & 9 & 12 & $g$ & 30 \\
\hline Dandeo Cily & UK & $\mathbf{9}$ & 10 & 10 & 29 \\
\hline Cowenty & $\mathrm{UK}$ & 9 & 8 & $\mathrm{~g}$ & 26 \\
\hline Fréjus & France & 9 & 8 & 8 & 25 \\
\hline $\begin{array}{c}\text { Annemasse Agglo (Cily } \\
\text { Reglen) }\end{array}$ & France & 7 & g & $\mathrm{g}$ & 25 \\
\hline Nico & France & 7 & 10 & 7 & 24 \\
\hline Eózicrs & France & $\mathbf{A}$ & 7 & $\mathrm{~g}$ & 24 \\
\hline Lincoln & $\mathrm{UK}$ & 2 & 0 & 22 & 24 \\
\hline Martigues & France & 7 & $g$ & 7 & 23 \\
\hline Hastings & UK & $\mathbf{E}$ & $\theta$ & $\mathrm{g}$ & 23 \\
\hline Aloi & France & 8 & $\theta$ & 6 & 22 \\
\hline Marsello & France & 5 & 8 & $\mathrm{~g}$ & 22 \\
\hline Glasgow & UK & 7 & 7 & B & 22 \\
\hline Luton & UK & 9 & 9 & 4 & 22 \\
\hline Monwich & UK & 5 & 9 & 0 & 22 \\
\hline Ax-en-Prauence & France & 7 & 7 & 7 & 21 \\
\hline Caroiff & $\mathrm{UK}$ & 5 & 8 & 8 & 21 \\
\hline Camoon & UK & $\mathbf{E}$ & 6 & $\mathrm{~g}$ & 21 \\
\hline $\begin{array}{c}\text { Chosh io brost and } \\
\text { Chaster }\end{array}$ & UK & 5 & B & 8 & 21 \\
\hline Crawlay & $\mathrm{UK}$ & 5 & 8 & 8 & 21 \\
\hline Valence & France & 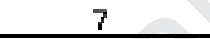 & 6 & 7 & 20 \\
\hline Mulhousc & France & 2 & 6 & $\theta$ & 20 \\
\hline Calars & France & $\mathbf{E}$ & 7 & 7 & 20 \\
\hline Loods & $\mathrm{UK}$ & 7 & 8 & 5 & 20 \\
\hline Potemo uth & UK & $\mathbf{E}$ & 6 & $\theta$ & 20 \\
\hline Hackngy & $\mathrm{UK}$ & 7 & 5 & 8 & 20 \\
\hline Cambriga & UK & $\mathbf{E}$ & 8 & 6 & 20 \\
\hline Brant & UK & 7 & 5 & 8 & 20 \\
\hline Easi Elafforoshire & $\mathrm{UK}$ & $\mathbf{E}$ & 6 & 8 & 20 \\
\hline Valenca & Spsin & 5 & 8 & 6 & 19 \\
\hline Hómin-Garvin & France & 5 & 7 & 7 & 19 \\
\hline York & $\mathrm{UK}$ & 4 & 6 & $\mathrm{~g}$ & 19 \\
\hline Ma nchossiser & UK & 4 & 7 & $\theta$ & 19 \\
\hline Bristol & $\mathrm{UK}$ & 5 & 7 & 7 & 19 \\
\hline Cholienham & UK & 4 & B & $\mathrm{g}$ & 19 \\
\hline $\begin{array}{c}\text { Bath and Worth East } \\
\text { Somersol }\end{array}$ & UK & $\mathbf{E}$ & 7 & 6 & 19 \\
\hline King년ㅇ-ıpon-H৬ll & $\mathrm{UK}$ & 8 & 4 & 7 & 19 \\
\hline Rouen & France & 8 & 4 & 6 & 18 \\
\hline Charbourg & France & 7 & 5 & 6 & 18 \\
\hline Le Hang & France & 7 & 5 & 6 & 18 \\
\hline Colchoster & Uk & E & 6 & 6 & 18 \\
\hline Stecdon-on-Teqs & $\mathrm{UK}$ & $\mathbf{B}$ & 4 & 8 & 18 \\
\hline
\end{tabular}


Journal Pre-proof

\begin{tabular}{|c|c|c|c|c|c|}
\hline Cily & Country & $\begin{array}{l}\text { Identifying and } \\
\text { Understanding } \\
\text { Sicore }\end{array}$ & $\begin{array}{l}\text { Enyision and } \\
\text { Planning } \\
\text { Scoro }\end{array}$ & $\begin{array}{l}\text { Implementation and } \\
\text { Monitoring Score }\end{array}$ & $\begin{array}{l}\text { Total } \\
\text { Score }\end{array}$ \\
\hline Cldinam & UK & 3 & 7 & 8 & 18 \\
\hline Rosang & $\mathrm{UK}$ & 6 & E & 6 & 18 \\
\hline Milodlosb rough & $\mathrm{UK}$ & 5 & 7 & $\mathrm{E}$ & 18 \\
\hline Torbay & $\mathrm{UK}$ & 6 & $E$ & 6 & 18 \\
\hline Gnamnitz & Gorman's: & 8 & 4 & 5 & 17 \\
\hline Aubagro & France & 8 & 4 & 5 & 17 \\
\hline $\begin{array}{l}\text { La rient Agglomaration } \\
\text { [Cly Ragion) }\end{array}$ & France & 3 & 5 & $\mathrm{~g}$ & 17 \\
\hline Perpgnan & France & 6 & $\mathrm{E}$ & 5 & 17 \\
\hline Warrington & UK & 6 & 4 & 7 & 17 \\
\hline Detry & $\mathrm{UK}$ & 2 & $E$ & 9 & 17 \\
\hline Becford & UK & 6 & 5 & 6 & 17 \\
\hline Wokng & UK & 6 & $E$ & 5 & 17 \\
\hline Tungndgo Wells & $\mathrm{UKK}$ & 2 & $\mathrm{E}$ & 7 & 17 \\
\hline $\begin{array}{c}\text { Tampore i Tammarfors } \\
\text { scoro }\end{array}$ & Firlang & 0 & E & 4 & 16 \\
\hline Turku i Aoo score & Firlang & 2 & 3 & 2 & 16 \\
\hline Timisoara & Roman!a & 5 & $E$ & 5 & 16 \\
\hline Bjdgoszaz & Polanc & 3 & 7 & 6 & 16 \\
\hline Charloville-Méziè-res & France & 6 & 5 & 5 & 16 \\
\hline 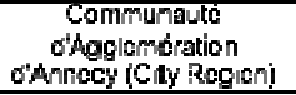 & France & 6 & 3 & 7 & 16 \\
\hline Basings toke and Deano & $\mathrm{UKK}$ & 9 & 5 & 90 & 16 \\
\hline Wgen & $\mathrm{IK}$ & 7 & 3 & 6 & 16 \\
\hline Thumock & $\mathrm{UKK}$ & 4 & 7 & 5 & 16 \\
\hline Wiral & UKK & 3 & $\mathrm{E}$ & 7 & 16 \\
\hline Harrow & $\mathrm{UK}$ & 3 & $E$ & 7 & 16 \\
\hline Tamworth & $\mathrm{UK}$ & 7 & 4 & 5 & 16 \\
\hline Dub| |n & Ireland & 3 & E & 8 & 15 \\
\hline Bruxelles & Bclgium & 1 & 4 & 10 & 15 \\
\hline Nancy & France & 4 & $\mathrm{C}$ & 2 & 15 \\
\hline Bsychno & France & 6 & 4 & 5 & 15 \\
\hline Chambery & France & 5 & 5 & 5 & 15 \\
\hline Solford & UK & $\bar{y}$ & 5 & 6 & 15 \\
\hline Wall ham Forest & $\mathrm{UK}$ & 6 & 4 & 5 & 15 \\
\hline Swindon & $\mathrm{uK}$ & 1 & $E$ & 8 & 15 \\
\hline Guldiora & $\mathrm{UK}$ & 7 & 3 & 5 & 15 \\
\hline Dudley & $\mathrm{UK}$ & 2 & 7 & $\mathrm{e}$ & 15 \\
\hline Brighion anc Houe & UKK & 4 & 5 & $\mathrm{E}$ & 15 \\
\hline Konsinglon and Cholsos & $\mathrm{UKK}$ & 5 & 2 & $\mathrm{e}$ & 15 \\
\hline Madric & Spain & 6 & 4 & 4 & 14 \\
\hline Nimes & Franco & 6 & 5 & 3 & 14 \\
\hline Darlington & $\mathbf{U K}$ & 3 & 5 & $\mathrm{E}$ & 14 \\
\hline Gloucester & $\underline{\mathrm{UK}}$ & 5 & 4 & 5 & 14 \\
\hline
\end{tabular}


Joumal Pre-proof

\begin{tabular}{|c|c|c|c|c|c|}
\hline Cily & Country & $\begin{array}{l}\text { Identifying and } \\
\text { Understanding } \\
\text { Sicore }\end{array}$ & $\begin{array}{c}\text { Envision and } \\
\text { Planning } \\
\text { Scone }\end{array}$ & $\begin{array}{l}\text { Implementation and } \\
\text { Monitoring Score }\end{array}$ & $\begin{array}{l}\text { Total } \\
\text { Score }\end{array}$ \\
\hline loswich & $\mathrm{UK}$ & 3 & $\mathrm{~g}$ & 3 & 14 \\
\hline Stovenago & $\mathrm{UKK}$ & 0 & 0 & 94 & 14 \\
\hline $\begin{array}{c}\text { HelFinki hetropel itar } \\
\text { Area scorg }\end{array}$ & Finlanc & 3 & 5 & 5 & 13 \\
\hline Essen & Gormar's & 2,5 & 6.5 & 4 & 13 \\
\hline Monipcil|igr & France & $g$ & 4 & 0 & 13 \\
\hline Dougi & France & 1 & 5 & 7 & 13 \\
\hline $\begin{array}{c}\text { Pays do Mo ntbéliard } \\
\text { Agglomeration (Cily } \\
\text { Region') }\end{array}$ & France & 0 & 4 & 8 & 13 \\
\hline Sclihull & UKK & 4 & $E$ & 3 & 13 \\
\hline Telford ane Wrekin & $\mathrm{UK}$ & 4 & 4 & 5 & 13 \\
\hline Warwick & UK & 2 & $E$ & 5 & 13 \\
\hline Bradiord & UK & 4 & 7 & 2 & 13 \\
\hline Slaugh & UK & 5 & 1 & 7 & 13 \\
\hline Hillingdon & $\mathrm{UK}$ & 5 & 2 & 6 & 13 \\
\hline Rothorham & $\mathrm{UK}$ & 2 & 3 & 8 & 13 \\
\hline Duisourg & German't' & 5 & e & 2 & 13 \\
\hline Angers & France & 5 & 7 & + & 12 \\
\hline Wals:all & $\mathrm{JK}$ & 7 & 2 & 3 & 12 \\
\hline Ashiord & UK & 9 & $E$ & + & 12 \\
\hline Eastbourne & UK & 3 & 4 & 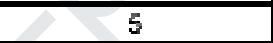 & 12 \\
\hline Finda um & 】K & 9 & 3 & 8 & 12 \\
\hline Oulu/ Lladborg sore & Firlang & 2 & 5 & 4 & 11 \\
\hline Valenciennos & France & 5 & E & 0 & 11 \\
\hline Boliort & France & 4 & 3 & 4 & 11 \\
\hline Angoulếme & France & 2 & 5 & 4 & 11 \\
\hline Chalon-sur-saóne & France & 6 & 2 & 3 & 11 \\
\hline Carlisise & $\mathrm{UK}$ & 2 & 3 & 6 & 11 \\
\hline Orleans & France & 5 & 5 & 0 & 10 \\
\hline Snofiloglo & $\overline{U K k}$ & 3 & 3 & 4 & 10 \\
\hline Groenwish & UKK & 9 & E & 1 & 10 \\
\hline Falk rk & IKK & 4 & $z$ & 4 & 10 \\
\hline Medwsy & $\mathrm{UKK}$ & 5 & 0 & 4 & 9 \\
\hline Bionn & Gorman't: & 3 & 3 & 3 & 9 \\
\hline Hurcola & Spgin & 2 & 4 & 3 & 9 \\
\hline Dijon & France & 4 & 5 & 0 & 9 \\
\hline Golmar & France & 9 & 4 & 4 & 9 \\
\hline Ârras & France & 2 & 3 & 4 & 9 \\
\hline Milion Keynes & UKK & 0 & 3 & 6 & 9 \\
\hline Oxford & UK & 2 & $\mathrm{E}$ & 1 & 9 \\
\hline Nantos & France & 2 & E & 0 & 8 \\
\hline Reims & France & 4 & 4 & 0 & 8 \\
\hline Glemprt-Fgrang & France & 4 & 4 & 0 & 8 \\
\hline Brost & France & 5 & 3 & 0 & 8 \\
\hline
\end{tabular}




\begin{tabular}{|c|c|c|c|c|c|}
\hline City & Country & $\begin{array}{l}\text { Identifying and } \\
\text { Understanding } \\
\text { Score }\end{array}$ & $\begin{array}{l}\text { Envision and } \\
\text { Planning } \\
\text { Scole }\end{array}$ & $\begin{array}{l}\text { Implementation and } \\
\text { Monitoring score }\end{array}$ & $\begin{array}{l}\text { Total } \\
\text { Score }\end{array}$ \\
\hline Havering & UK & 1 & 3 & 4 & 8 \\
\hline North Tynosico & UK & 9 & 3 & 4 & 8 \\
\hline Eracknell Fores: & UK & 3 & 3 & 2 & 8 \\
\hline Plymouth & UK & 2 & 4 & 2 & 8 \\
\hline Gatosheas & JK & 9 & 4 & 2 & 7 \\
\hline Exator & JK & 0 & 4 & 3 & 7 \\
\hline St Albans & UK & 1 & 4 & 2 & 7 \\
\hline Elono: Elx & Spain & 9 & 4 & 1 & 6 \\
\hline Razas de Mladrid, Las & Spain & 0 & 2 & 3 & 5 \\
\hline Poitiers & France & 3 & 2 & 0 & 5 \\
\hline Gremc ble & France & 1 & 4 & 0 & 5 \\
\hline Sandwcll & UK & 0 & 2 & 3 & 5 \\
\hline Boxloy & UK & 0 & 3 & 2 & 5 \\
\hline Kirkleos & UK & 2 & 2 & 1 & 5 \\
\hline Lyon & France & 1 & 3 & 0 & 4 \\
\hline Bordeaux & France & 1 & 3 & 0 & 4 \\
\hline Sa in-Erionno & France & 0 & $\overline{3}$ & 1 & 4 \\
\hline Limogos & France & 2 & 2 & 0 & 4 \\
\hline Lo Have & France & 9 & 2 & 0 & 3 \\
\hline Saint Donis & France & 2 & 1 & 0 & 3 \\
\hline yolz & France & 0 & 2 & 0 & 2 \\
\hline Eoliast & UK & 0 & 1 & 1 & 2 \\
\hline
\end{tabular}


- Review and assessment of the level of integration of adaptation and mitigation in 147 European urban climate change action plans

- Development and application of the Urban Climate Change Integration Index (UCCII)

- Review and analysis of synergies and co-benefits of climate mitigation and adaptation actions

- Mitigation objectives are still more prominent than adaptation objectives in integrated urban climate change plans

- Discussion on capacity gaps and needs of local governments on understanding, planning and implementation stages of integrated approaches 